\title{
Analytical Solution of Deformations for Two-Layer Timoshenko Beams Glued by a Viscoelastic Interlayer
}

\author{
Zhiyi Pei, Lin Wang, Peng Wu, Jiandong Zhang, and Ding Zhou \\ College of Civil Engineering, Nanjing Tech University, Nanjing 211816, China \\ Correspondence should be addressed to Ding Zhou; dingzhou57@yahoo.com
}

Received 29 January 2019; Revised 25 March 2019; Accepted 4 April 2019; Published 18 April 2019

Academic Editor: Francesco Clementi

Copyright (C) 2019 Zhiyi Pei et al. This is an open access article distributed under the Creative Commons Attribution License, which permits unrestricted use, distribution, and reproduction in any medium, provided the original work is properly cited.

\begin{abstract}
An analytical solution of stresses and deformations for two-layer Timoshenko beams glued by a viscoelastic interlayer under uniform transverse load is presented. The standard linear solid model is employed to simulate the viscoelastic characteristics of the interlayer, in which the memory effect of strains is considered. The mechanical behavior of each layer is described by the first-order shear deformation theory (FSDT). By means of the principle of minimum potential energy, a group of equations for displacements and rotation angles are derived out. The final solution is obtained by conducting the Laplace transform and the inversion of Laplace transform to the equation group. Numerical comparison shows that the present solutions and the finite element results are in good agreement. It is shown that the present results are more accurate than those obtained from the Euler-Bernoulli beam theory, especially for thick beams. And the present solutions can accurately describe the variation of stresses and deformations of the beam with the time, compared with those ignoring the memory effect of strains. Finally, the effects of the geometric parameters and material properties of the interlayer on stresses and deformations of the beam are studied in detail.
\end{abstract}

\section{Introduction}

Owing to excellent combination advantages, layered composite structures are extensively used in civil engineering. The common applications are steel-concrete composite beams $[1,2]$, wood-concrete composite panels $[3,4]$, fiber reinforced concrete $[5,6]$, laminated glasses $[7,8]$, and so on. The existing analysis indicates that the interface connection property has considerable impact on the stresses and deformations in the layered structures $[9,10]$. Behr et al. [11] studied the temperature effect on behavior of laminated glass. Galuppi and Royer-Carfagni [12] studied the effective width of equivalent slab for composite beam with shear connectors. In practical engineering, the adhesives are sometimes used to connect several structural components to form a composite structure. For the viscoelastic materials, the dependence of the stress state on the strain history is intrinsic. This study focuses on the mechanical behavior of two-layer beams glued by adhesives. The adhesives possess viscoelastic characteristics in nature, and thus the mechanical properties of the layered beams are time-varying and even subjected to static loads.
As is known to all, the Euler-Bernoulli (EB) beam theory assumes that the cross sections in the beam remain plane and perpendicular to the neutral axis during deformation. Based on this theory, several studies can be found for layered beams glued by viscoelastic interlayer. Zhang and Wang [13] analyzed the viscoelastic property of concrete beams reinforced by fiber reinforced polymers and gave the analytical solutions by the use of the numerical Laplace transformation method. Lei [14] studied the dynamic characteristics of damped viscoelastic nonlocal EB beams with different boundary conditions by the use of the transfer function method. Wang [15] presented the analytical solutions for bending behavior of viscoelastic beams under quasi-static loading. Bending and buckling behaviors of layered beams glued by viscoelastic interlayer were investigated by Galuppi and Royer-Carfagni $[16,17]$. In their report, two kinds of analytical models for the interlayer were proposed: the fully viscoelastic model considering the memory effect of strains and the quasi-elastic model ignoring the memory effect of strains (the viscoelastic material is approximately modelled as an "aging" material). $\mathrm{Li}$ [18] investigated the time-varying behaviors of layered 


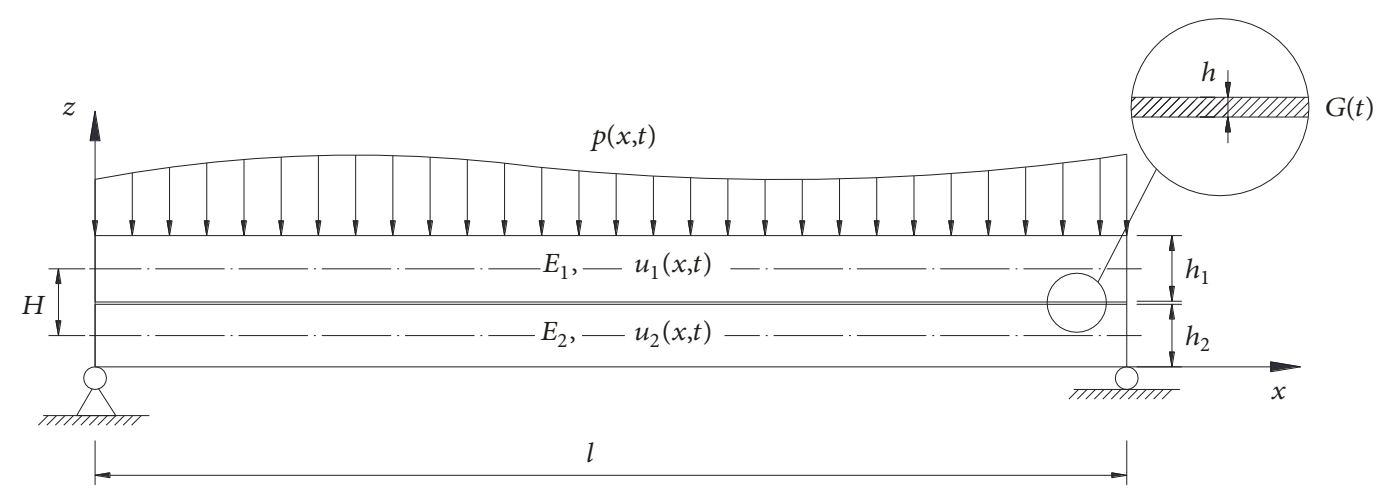

FIGURE 1: Simply supported two-layer beam glued by a viscoelastic interlayer.

functionally graded beams with viscoelastic interlayer by using the analytical Laplace transformation.

However, the transverse shear deformation is ignored in the EB beam theory, which will lead to imprecise results when the transverse shear deformations are considerable, such as deep beams. In order to consider the transverse shear deformations, the first-order shear deformation theory (FSDT) was proposed. This theory assumes that the transverse shear strain exists and is invariable along the beam thickness. We call such a beam as the Timoshenko beam. Based on the FSDT theory, Lenci and Clementi [19] studied the natural frequency of layered beams sandwiching an elastic interlayer. Murakami [20] presented a laminated Timoshenko theory which considers the interlayer slip in the beam. Wang [21] studied the vibration and damping effect in a three-layered composite annular plate with a viscoelastic interlayer based on the FSDT theory. Bardella [22] studied the reliability of FSDT model for sandwich beams. Mattei and Bardella [23] and Tessler et al. [24] developed the structural analysis for sandwich beams based on the zigzag model. Frostig et al. [25] studied the behavior of sandwich beams based on the high-order theory. The investigation of bending response for functionally graded viscoelastic sandwich beam with elastic core resting on Pasternak's elastic foundations was presented by Zenkour [26]. Arikoglu [27] dealt with the vibration of a three-layered composite beam with a viscoelastic core by using the differential transform method. The analytical solutions of stresses and displacements of twolayer Timoshenko beams connected by viscoelastic interlayer, whose memory effect of strains was ignored, were studied by Wang et al. [28]. Aenlle and Pelayo [29, 30] studied the dynamic effective thickness of laminated-glass beams and plates. Serpilli and Lenci [31-33] developed the asymptotic expansion method to study the mechanical properties of three-layer beams and plates with soft adhesive.

In the present study, we extend the study from [16] on the slender layered beams with viscoelastic interlayer to the thick layered beams with viscoelastic interlayer. The motivation is to analyze the shear effect of length-to-thickness ratio on the deformations of the layered beams. An analytical solution based on the FSDT is developed for a two-layer Timoshenko beam glued by epoxy. The memory effect of the strains of the interlayer material is considered in the analysis. A very simple model, the standard linear solid model (SLSM), is used to model the viscoelasticity of the epoxy interlayer. The deformation and rotation angle of each beam layer are described in terms of the FSDT. The viscoelastic property in the interlayer is simulated by the standard linear solid model. By means of the principle of minimum potential energy and the Laplace transformation, the solutions of deformations and rotation angles are obtained analytically.

\section{Analytical Model}

Consider a simply supported layered beam of length $l$ and width $b$ as shown in Figure 1, consisting of two external elastic layers with thicknesses $h_{1}$ and $h_{2}$ adhesively glued by a thin epoxy with thickness $h$, subjected to transverse distributed load $p(x, t) . H$ is the distance between the geometric axes of upper and lower layers. A Cartesian coordinate system is established with origin at the bottom surface of the beam. The elastic moduli of two external layers are $E_{1}$ and $E_{2}$, and Poisson's ratios are $\mu_{1}$ and $\mu_{2}$, respectively. For isotropic materials, the shear modulus in the beam layers is expressed by $G_{i}=E_{i} / 2\left(1+\mu_{i}\right), i=1,2$. The shear modulus of the epoxy interlayer is time-dependent and denoted by $G(t)$ [34].

2.1. Assumptions. The present study is carried out based on the following assumptions:

(i) The strain and displacement in the beam are small.

(ii) The interlayer is very thin with respect to the external layers. The shear stress is constant along its thickness.

(iii) The transverse displacements and rotation angles of external elastic layers are the same, but the axial displacements about the geometric axis of each layer are different.

(iv) Since the interlayer, made of viscoelastic adhesives, is relatively soft than the beam layer, the longitudinal normal stress and strain in the interlayer are negligible.

2.2. Basic Equations. According to the first-order shear deformation theory (FSDT), the longitudinal displacement 
$u(x, z, t)$ and the transverse displacement $w(x, z, t)$ of the layered beam are given by

$$
\begin{aligned}
& u(x, z, t) \\
& = \begin{cases}u_{1}(x, t)-\left(z-z_{1}\right) \varphi(x, t) & \left(h_{2}+h \leq z \leq h_{2}+h+h_{1}\right) \\
u_{2}(x, t)-\left(z-z_{2}\right) \varphi(x, t) & \left(0 \leq z \leq h_{2}\right),\end{cases} \\
& w(x, z, t)=w(x, t),
\end{aligned}
$$

where $u_{1}(x, t)$ and $u_{2}(x, t)$ are displacements at geometric axes of upper and lower layers, respectively; $\varphi(x, t)$ is the rotation angle of transverse cross-section of the layered beam; $w(x, t)$ is the deflection of the layered beam; $t$ denotes time. $z_{1}$ and $z_{2}$ are the distances from the geometric axes of upper and lower layers to the bottom surface of the beam, and $z_{1}=$ $h_{1} / 2+h+h_{2}, z_{2}=h_{2} / 2$. The longitudinal normal strain $\varepsilon_{x x}$ and the transverse shear strain $\gamma_{x z}$ in the beam are given by

$$
\begin{aligned}
& \varepsilon_{x x}(x, z, t) \\
& = \begin{cases}\frac{\partial u_{1}(x, t)}{\partial x}-\left(z-z_{1}\right) \frac{\partial \varphi(x, t)}{\partial x} & \left(h_{2}+h \leq z \leq h_{2}+h+h_{1}\right) \\
\frac{\partial u_{2}(x, t)}{\partial x}-\left(z-z_{2}\right) \frac{\partial \varphi(x, t)}{\partial x} & \left(0 \leq z \leq h_{2}\right),\end{cases} \\
& \gamma_{x z}(x, z, t)=\frac{\partial w(x, t)}{\partial x}-\varphi(x, t) .
\end{aligned}
$$

The longitudinal normal stress $\sigma_{x x}$ and the transverse shear stress $\tau_{x z}$ in the beam are further obtained by

$$
\begin{gathered}
\sigma_{x x}(x, z, t)=E \varepsilon_{x x}(x, z, t)= \begin{cases}E_{1}\left[\frac{\partial u_{1}(x, t)}{\partial x}-\left(z-z_{1}\right) \frac{\partial \varphi(x, t)}{\partial x}\right] & \left(h_{2}+h \leq z \leq h_{2}+h+h_{1}\right) \\
E_{2}\left[\frac{\partial u_{2}(x, t)}{\partial x}-\left(z-z_{2}\right) \frac{\partial \varphi(x, t)}{\partial x}\right] & \left(0 \leq z \leq h_{2}\right)\end{cases} \\
\tau_{x z}(x, z, t)=\frac{G}{k} \gamma_{x z}(x, z, t)= \begin{cases}\frac{G_{1}}{k_{1}}\left(\frac{\partial w(x, t)}{\partial x}-\varphi(x, t)\right) & \left(h_{2}+h \leq z \leq h_{2}+h+h_{1}\right) \\
\frac{G_{2}}{k_{2}}\left(\frac{\partial w(x, t)}{\partial x}-\varphi(x, t)\right) & \left(0 \leq z \leq h_{2}\right)\end{cases}
\end{gathered}
$$

where $k_{1}$ and $k_{2}$ are, respectively, the shear coefficients in FSDT for the upper and lower beam layers. For beams with rectangular cross-section, the shear coefficients can be given as [35]

$$
k=\frac{10(1+\mu)}{12+11 \mu}
$$

where $\mu$ is Poisson's ratio of materials of the upper and lower elastic layer. We assume that the internal interlayer is very thin with respect to the external plies. This leads to constant shear stress along the thickness of the interlayer. For an elastic material, the longitudinal shear strain $\gamma_{0}(x, t)$ and shear stress $\tau_{0}(x, t)$ in the interlayer can be expressed by the deformation and rotation angle in the upper and lower beam layers [36], as follows:

$$
\begin{aligned}
& \gamma_{0}(x, t)=\frac{1}{h}\left[u_{1}(x, t)-u_{2}(x, t)+\varphi(x, t) H\right], \\
& \tau_{0}(x, t)=\frac{G(t)}{h}\left[u_{1}(x, t)-u_{2}(x, t)+\varphi(x, t) H\right]
\end{aligned}
$$

where $H$ is the distance between the geometric axes of the upper and lower layers and $H=h_{1} / 2+h+h_{2} / 2 . G(t)$ is the shear modulus of the interlayer.
In Cartesian coordinates, the strain energy in the beam can be written as

$$
\begin{aligned}
U & =\frac{1}{2} \int_{0}^{l} \int_{A}\left[\sigma_{x x}(x, z, t) \varepsilon_{x x}(x, z, t)\right. \\
& +\tau_{x z}(x, z, t) \gamma_{x z}(x, z, t) \\
& \left.+\tau_{0}(x, t) \gamma_{0}(x, t)\right] d A d x
\end{aligned}
$$

where $A$ is the cross-sectional area of the beam. The energy of the system is given by

$$
\Pi=\int_{0}^{l} L d x
$$

where $L$ is the Lagrange density function, which is

$$
\begin{aligned}
L= & \frac{1}{2}\left\{R_{1}\left(\frac{\partial u_{1}}{\partial x}\right)^{2}+R_{2}\left(\frac{\partial u_{2}}{\partial x}\right)^{2}\right. \\
& +\left(D_{1}+D_{2}\right)\left(\frac{\partial \varphi}{\partial x}\right)^{2}+B_{1}\left(\frac{\partial w}{\partial x}-\varphi\right)^{2} \\
& \left.+\frac{b G(t)}{h}\left[u_{1}(x, t)-u_{2}(x, t)+\varphi(x, t) H\right]^{2}\right\} \\
& +p(x) w(x, t) b
\end{aligned}
$$

where $R_{1}$ and $R_{2}$ are the extensional rigidities, $D_{1}$ and $D_{2}$ are the bending rigidities for upper and lower beam layers, and $B_{1}$ 
is the shearing rigidity of the whole beam. These parameters can be expressed as

$$
\begin{aligned}
& R_{1}=E_{1} b h_{1}, \\
& R_{2}=E_{2} b h_{2}, \\
& D_{1}=\frac{E_{1} b h_{1}^{3}}{12}, \\
& D_{2}=\frac{E_{2} b h_{2}^{3}}{12}, \\
& B_{1}=\frac{b G_{1} h_{1}}{k_{1}}+\frac{b G_{2} h_{2}}{k_{2}}
\end{aligned}
$$

Lagrange's equations for the beam are

$$
\begin{gathered}
\frac{\partial}{\partial x}\left(\frac{\partial L}{\partial u_{1}^{\prime}}\right)-\frac{\partial L}{\partial u_{1}}=0, \\
\frac{\partial}{\partial x}\left(\frac{\partial L}{\partial u_{2}^{\prime}}\right)-\frac{\partial L}{\partial u_{2}}=0, \\
\frac{\partial}{\partial x}\left(\frac{\partial L}{\partial \varphi^{\prime}}\right)-\frac{\partial L}{\partial \varphi}=0, \\
\frac{\partial}{\partial x}\left(\frac{\partial L}{\partial w^{\prime}}\right)-\frac{\partial L}{\partial w}=0
\end{gathered}
$$

Equilibrium equations can be obtained by substituting (9) into (11), as follows:

$$
\begin{aligned}
& R_{1} u_{1}^{\prime \prime}(x, t)-b \tau_{0}(x, t)=0, \\
& R_{2} u_{2}^{\prime \prime}(x, t)+b \tau_{0}(x, t)=0 \\
& \left(D_{1}+D_{2}\right) \varphi^{\prime \prime}(x, t)+B_{1}\left[w^{\prime}(x, t)-\varphi(x, t)\right] \\
& \quad-b H \tau_{0}(x, t)=0 \\
& B_{1}\left[w^{\prime \prime}(x, t)-\varphi^{\prime}(x, t)\right]-p(x) b=0
\end{aligned}
$$

Considering the memory effect of strains in the interlayer, the constitutive equation for viscoelastic interlayer can be obtained by the Boltzmann superposition principle [37], as follows:

$$
\begin{aligned}
\tau_{0}(x, t) & =G(t) \gamma_{0}(x, 0)+\int_{0}^{t} G(t-\xi) \frac{\partial \gamma_{0}(x, \xi)}{\partial \xi} d \xi \\
& =G(0) \gamma_{0}(x, t)+\int_{0}^{t} \frac{d G(t-\xi)}{d(t-\xi)} \gamma_{0}(x, \xi) d \xi
\end{aligned}
$$

It can be seen that the stresses at one point not only depend on the strains at that moment, but also depend on the whole strain history. According to the Riemann-Stieltjes convolution [38, 39], (15) can be rewritten as

$$
\tau_{0}(x, t)=\gamma_{0}(x, t) * d G(t)
$$

in which $*$ means convolution.
By substituting (16) into (12)-(14), one has

$$
\begin{aligned}
& R_{1} u_{1}^{\prime \prime}(x, t)-b \gamma_{0}(x, t) * d G(t)=0, \\
& R_{2} u_{2}^{\prime \prime}(x, t)+b \gamma_{0}(x, t) * d G(t)=0 \\
& \left(D_{1}+D_{2}\right) \varphi^{\prime \prime}(x, t)+B_{1}\left[w^{\prime}(x, t)-\varphi(x, t)\right] \\
& \quad-b H \gamma_{0}(x, t) * d G(t)=0 \\
& B_{1}\left[w^{\prime \prime}(x, t)-\varphi^{\prime}(x, t)\right]-p(x) b=0
\end{aligned}
$$

\section{Analytical Solution}

3.1. Formulation of Solution. The boundary conditions of simply supported beams at $x=0, l$ are given as

$$
\begin{aligned}
& u_{1}^{\prime}(0, t)=u_{1}^{\prime}(l, t)=0, \\
& u_{2}^{\prime}(0, t)=u_{2}^{\prime}(l, t)=0, \\
& \varphi^{\prime}(0, t)=\varphi^{\prime}(l, t)=0, \\
& w(0, t)=w(l, t)=0
\end{aligned}
$$

Here, we expand the displacements, rotation angles, and applied loads of the beam into Fourier series, as follows:

$$
\begin{aligned}
u_{1}(x, t) & =\sum_{j=1}^{M} a_{j}(t) \cos \left(\lambda_{j} x\right), \\
u_{2}(x, t) & =\sum_{j=1}^{M} b_{j}(t) \cos \left(\lambda_{j} x\right) \\
\varphi(x, t) & =\sum_{j=1}^{M} c_{j}(t) \cos \left(\lambda_{j} x\right), \\
w(x, t) & =\sum_{j=1}^{M} d_{j}(t) \sin \left(\lambda_{j} x\right) \\
p(x) & =\sum_{j=1}^{M} p_{j} \sin \left(\lambda_{j} x\right), \\
p_{j} & =\frac{2}{l} \int_{0}^{l} p(x) \sin \left(\lambda_{j} x\right) d x
\end{aligned}
$$

where $a_{j}(t), b_{j}(t), c_{j}(t)$, and $d_{j}(t)$ are the unknown Fourier coefficients and $\lambda_{j}=j \pi / l$. By substituting (21)- (23) into (17)(19), we obtain

$$
\begin{aligned}
& -R_{1} \lambda_{j}^{2} a_{j}(t)-\frac{b}{h}\left[a_{j}(t)-b_{j}(t)+H c_{j}(t)\right] \\
& * d G(t)=0
\end{aligned}
$$




$$
\begin{aligned}
& -R_{2} \lambda_{j}^{2} b_{j}(t)+\frac{b}{h}\left[a_{j}(t)-b_{j}(t)+H c_{j}(t)\right] \\
& * d G(t)=0 \\
& -\left(D_{1}+D_{2}\right) \lambda_{j}^{2} c_{j}(t)+B_{1}\left[\lambda_{j} d_{j}(t)-c_{j}(t)\right] \\
& -\frac{b H}{h}\left[a_{j}(t)-b_{j}(t)+H c_{j}(t)\right] * d G(t)=0 \\
& B_{1}\left[-\lambda_{j}^{2} d_{j}(t)+\lambda_{j} c_{j}(t)\right]-b p_{j}(t)=0
\end{aligned}
$$

Several models, which can comprehensively describe the viscoelastic properties of materials, were developed for polymers $[16,40]$. It is found that the standard linear solid (SLS) model is suitable for simulating the viscoelastic property of some adhesives such as epoxy [34]. The SLS model, as shown in Figure 2, consists of a Maxwell Model and a Hookean spring in parallel. Notations $\eta$ and $G_{0}$ represent the viscosity coefficient and the relaxation shear modulus and $G_{\infty}$ is the long-term shear modulus. By using this model, the timedependent shear modulus $G(t)$ in the interlayer is given by

$$
G(t)=G_{\infty}+G_{0} e^{-t / \theta}
$$

where $\theta=\eta / G_{0}$ is the relaxation time. The shear stress $\tau_{0}(x, t)$ of the viscoelastic interlayer is further expressed by

$$
\begin{aligned}
& \tau_{0}(x, t)=\frac{G_{\infty}+G_{0}}{h}\left[u_{1}(x, t)-u_{2}(x, t)+\varphi(x, t) H\right] \\
& -\frac{G_{0}}{h \theta} \\
& \quad \cdot \int_{0}^{t} e^{-(t-\xi) / \theta}\left[u_{1}(x, \xi)-u_{2}(x, \xi)+\varphi(x, \xi) H\right] d \xi
\end{aligned}
$$

3.2. Laplace Transformation. By conducting the Laplace transforms to (24)- (27), one has

$$
\left[\begin{array}{cccc}
-R_{1} \lambda_{j}^{2}-\frac{b}{h} s \bar{G}(\mathrm{~s}) & \frac{b}{h} s \bar{G}(\mathrm{~s}) & -\frac{b H}{h} s \bar{G}(\mathrm{~s}) & 0 \\
\frac{b}{h} s \bar{G}(\mathrm{~s}) & -R_{2} \lambda_{j}^{2}-\frac{b}{h} s \bar{G}(\mathrm{~s}) & \frac{b H}{h} s \bar{G}(\mathrm{~s}) & 0 \\
-\frac{b H}{h} s \bar{G}(\mathrm{~s}) & \frac{b H}{h} s \bar{G}(\mathrm{~s}) & -\left(D_{1}+D_{2}\right) \lambda_{j}^{2}-B_{1}-\frac{b H^{2}}{h} s \bar{G}(\mathrm{~s}) & B_{1} \lambda_{j} \\
0 & 0 & B_{1} \lambda_{j} & -B_{1} \lambda_{j}^{2}
\end{array}\right]\left\{\begin{array}{l}
\bar{a}_{j}(\mathrm{~s}) \\
\bar{b}_{j}(\mathrm{~s}) \\
\bar{c}_{j}(\mathrm{~s}) \\
\bar{d}_{j}(\mathrm{~s})
\end{array}\right\}=\left\{\begin{array}{c}
0 \\
0 \\
0 \\
b \bar{p}_{j}(\mathrm{~s})
\end{array}\right\}
$$

in which $s$ is the Laplace transform variable, $\bar{G}(s)=G_{\infty} / s+$ $G_{0} /(s+1 / \theta)$. The solution of $(30)$ is

$$
\begin{aligned}
& \bar{a}_{j}(s)=\frac{C_{4} b s \bar{G}(s) \bar{p}_{j}(s)}{\lambda_{j}^{3}\left[C_{1} s \bar{G}(s)+C_{2} \lambda_{j}^{2}+C_{3} s \bar{G}(s)\right]} \\
& \bar{b}_{j}(s)=-\frac{C_{5} b s \bar{G}(s) \bar{p}_{j}(s)}{\lambda_{j}^{3}\left[C_{1} s \bar{G}(s)+C_{2} \lambda_{j}^{2}+C_{3} s \bar{G}(s)\right]} \\
& \bar{c}_{j}(s)=-\frac{b \bar{p}_{j}(s)\left[C_{6} \lambda_{j}^{2}+C_{7} s \bar{G}(s)\right]}{\lambda_{j}^{3}\left[C_{1} s \bar{G}(s)+C_{2} \lambda_{j}^{2}+C_{3} s \bar{G}(s)\right]} \\
& \bar{d}_{j}(s)=-\frac{b \bar{p}_{j}(s)}{B_{1} \lambda_{j}^{2}}-\frac{b \bar{p}_{j}(s)\left[C_{6} \lambda_{j}^{2}+C_{7} s \bar{G}(s)\right]}{\lambda_{j}^{4}\left[C_{1} s \bar{G}(s)+C_{2} \lambda_{j}^{2}+C_{3} s \bar{G}(s)\right]}
\end{aligned}
$$

where

$$
\begin{aligned}
& C_{1}=\left(R_{1}+R_{2}\right)\left(D_{1}+D_{2}\right) b, \\
& C_{2}=R_{1} R_{2}\left(D_{1}+D_{2}\right) h, \\
& C_{3}=R_{1} R_{2} H^{2} b, \\
& C_{4}=R_{2} H b, \\
& C_{5}=R_{1} H b,
\end{aligned}
$$

$$
\begin{aligned}
& C_{6}=R_{1} R_{2} h, \\
& C_{7}=\left(R_{1}+R_{2}\right) b
\end{aligned}
$$

3.3. Determination of Unknowns. Making the inverse of Laplace transforms to (31)-(34) gives

$$
\begin{aligned}
& a_{j}(t)=C_{1 j}+C_{2 j} e^{-C_{3 j} t}, \\
& b_{j}(t)=-C_{4 j}-C_{5 j} e^{-C_{3 j} t}, \\
& c_{j}(t)=-C_{6 j}-C_{7 j} e^{-C_{3 j} t}, \\
& d_{j}(t)=-C_{8 j}-C_{9 j}-C_{10 j} e^{-C_{3 j} t}
\end{aligned}
$$

The analytical expressions of coefficients in the above equations are given in the Appendix.

Substituting these coefficients back to (21), (22), (3), and (29), the final expressions of the displacements, rotation angles, longitudinal normal stress of the beam, and the shear stresses in the interlayer can be obtained, respectively.

\section{Numerical Examples}

4.1. Convergence Study. Consider a simply supported beam subjected to the uniform load $q=1 \mathrm{~N} / \mathrm{mm}^{2}$. The two external 
TABLE 1: Comparisons of maximum deflection $w_{m}$ from the present results (TFV) with the EFV and FE ones for different length-to-thickness ratios $l / h_{0}$ and time values $t$.

\begin{tabular}{|c|c|c|c|c|c|c|}
\hline$l / h_{0}$ & $t$ & TFV & EFV & $\mathrm{FE}$ & Error to EFV (\%) & Error to FE (\%) \\
\hline \multirow[t]{3}{*}{20} & $10 \mathrm{~s}$ & -28.4128 & -28.2849 & -28.5083 & 0.450 & 0.3361 \\
\hline & $100 \mathrm{~s}$ & -30.0366 & -29.9087 & -30.1347 & 0.426 & 0.3264 \\
\hline & $1000 \mathrm{~s}$ & -39.3301 & -39.2022 & -39.4403 & 0.325 & 0.2802 \\
\hline \multirow[t]{3}{*}{10} & $10 \mathrm{~s}$ & -1.8391 & -1.8072 & -1.847 & 1.739 & 0.4281 \\
\hline & $100 \mathrm{~s}$ & -2.2298 & -2.1979 & -2.2378 & 1.434 & 0.3566 \\
\hline & $1000 \mathrm{~s}$ & -3.9382 & -3.9062 & -3.9458 & 0.812 & 0.1934 \\
\hline \multirow[t]{3}{*}{5} & $10 \mathrm{~s}$ & -0.1306 & -0.1226 & -0.1313 & 6.123 & 0.5641 \\
\hline & $100 \mathrm{~s}$ & -0.2147 & -0.2067 & -0.2151 & 3.724 & 0.1930 \\
\hline & $1000 \mathrm{~s}$ & -0.3745 & -0.3665 & -0.3748 & 2.134 & 0.0726 \\
\hline \multirow[t]{3}{*}{2.5} & $10 \mathrm{~s}$ & -0.0119 & -0.0099 & -0.0118 & 16.81 & 0.5059 \\
\hline & $100 \mathrm{~s}$ & -0.0241 & -0.0221 & -0.0239 & 8.270 & 0.7887 \\
\hline & $1000 \mathrm{~s}$ & -0.0282 & -0.0262 & -0.0281 & 7.075 & 0.2485 \\
\hline
\end{tabular}

Note: Error to EFV=(EFV-TFV)/TFV; Error to FE=(FE-TFV)/TFV.

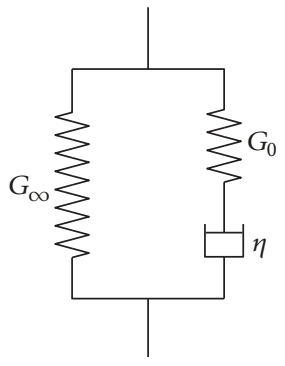

FIGURE 2: Standard linear solid model

layers of the beam are elastic ones and the interlayer is viscoelastic one. The parameters of the beam are $h_{1}=h_{2}=50 \mathrm{~mm}$, $h=0.1 \mathrm{~mm}, b=30 \mathrm{~mm}, l=500 \mathrm{~mm}, E_{1}=E_{2}=70 \mathrm{Gpa}, \mu_{1}=\mu_{2}=0.3$, $G_{0}=470.529 \mathrm{Mpa}, G_{\infty}=0.471 \mathrm{Mpa}$ and $\theta=1 \mathrm{~s}$. The terms of Fourier series are truncated up to $M$. The convergences of $\sigma_{x x}, \tau_{0}, u, w$ at different points when $t=300 \mathrm{~s}$ and 10000 $s$, respectively, are given in Figure 3. It can be seen from Figure 3 that the stresses and displacements rapidly converge to constants with the increase of $M$. When $M \geqslant 30$, a satisfied accuracy has been obtained. Thus, the terms of Fourier series is fixed at $M=30$ in the following studies unless stated.

4.2. Comparison Study. The present results (TFV) based on the Timoshenko beam theory are compared with those (EFV) based on the EB beam theory proposed by Galuppi and Royer-Carfagni [16] and those (FE) obtained from the finite element solutions by using the software ANSYS. The parameters of the beam are $E_{1}=E_{2}=70 \mathrm{Gpa}, G_{0}=470.529 \mathrm{Mpa}$, $G_{\infty}=0.471 \mathrm{Mpa}, \theta=1 \mathrm{~s}, \mu_{1}=\mu_{2}=0.3, h_{1}=h_{2}=50 \mathrm{~mm}, h=0.1 \mathrm{~mm}$, and $b=30 \mathrm{~mm}$, respectively. The load distribution is $q(x)=$ $\sin (\pi x / l) \mathrm{N} / \mathrm{mm}^{2}$ and the length $l$ of the beam is variable. In the FE modelling, the viscoelastic property of the interlayer is simulated by VISCO-88 element with four nodes, which can consider the memory effect of viscoelasticity. The PLANE183 element with four nodes is used for the external layers. Considering the thickness of the interlayer only to be $0.1 \mathrm{~mm}$, the length and width of rectangular elements for interlayer are fixed at $0.5 \mathrm{~mm}$ and $0.1 \mathrm{~mm}$, respectively. Considering the external layers are much thicker than the interlayer, the length and width of rectangular elements for external layers are fixed at $0.5 \mathrm{~mm}$ and $2.5 \mathrm{~mm}$, respectively. Taking the beam with the length-to-thickness ratio to be 10 as example, 2000 elements for the interlayer and 80000 elements for the external layers should be used in the FE computations. Table 1 gives the comparisons of mid-span deflection $w_{m}$ between the TFV solutions with the EFV and FE ones for different length-tothickness ratios $l / h_{0}$, where $h_{0}$ is the total thickness of the whole beam, $h_{0}=h_{1}+h+h_{2}$. Three different time values, $t=10$ s, 100 s, 1000 s, are considered, respectively. It can be seen from Table 1 that there are good agreements between the TFV results and the FE results. The maximum error is less than $0.5641 \%$ for all cases. Furthermore, it is seen that the TFV results coincide with the EFV ones well for slender beams; however, the difference significantly increases in the decrease of $l / h_{0}$, especially at the initial time of applying load. The maximum error of $w_{m}$ reaches $16.806 \%$ for $l / h_{0}=2.5$ when the load is at first applied to the beam. The maximum error of $w_{m}$ reaches $7.075 \%$ for $l / h_{0}=2.5$ when the interlayer is fully relaxed. Figure 4 gives the comparisons of $w_{m}$ between the TFV results with the EFV and FE ones when $t=10000$ $s$ with respect to length-to-thickness ratio $l / h_{0}$. It can be seen from Figure 4 that, for the small length-to-thickness ratios $l / h_{0}$, the TFV results obviously have a better accuracy than the EFV ones. Tables 2 and 3 give the comparisons of the maximum longitudinal normal stress $\sigma_{x x}$ and the maximum shear stress $\tau_{0}$ between the TFV solutions with the EFV and FE ones for different length-to-thickness ratios $l / h_{0}$, respectively. It can be seen from Tables 2 and 3 that the results from the TFV solutions are the same as those from the EFV solutions. This can be reasonably explained. For a simply supported layered beam considered here, the shear forces and moments at cross-section of the beam can be directly determined by only considering the force equilibrium. It is well known that both the Euler-Bernoulli beam theory and the Timoshenko beam theory follow the plane cross-section 

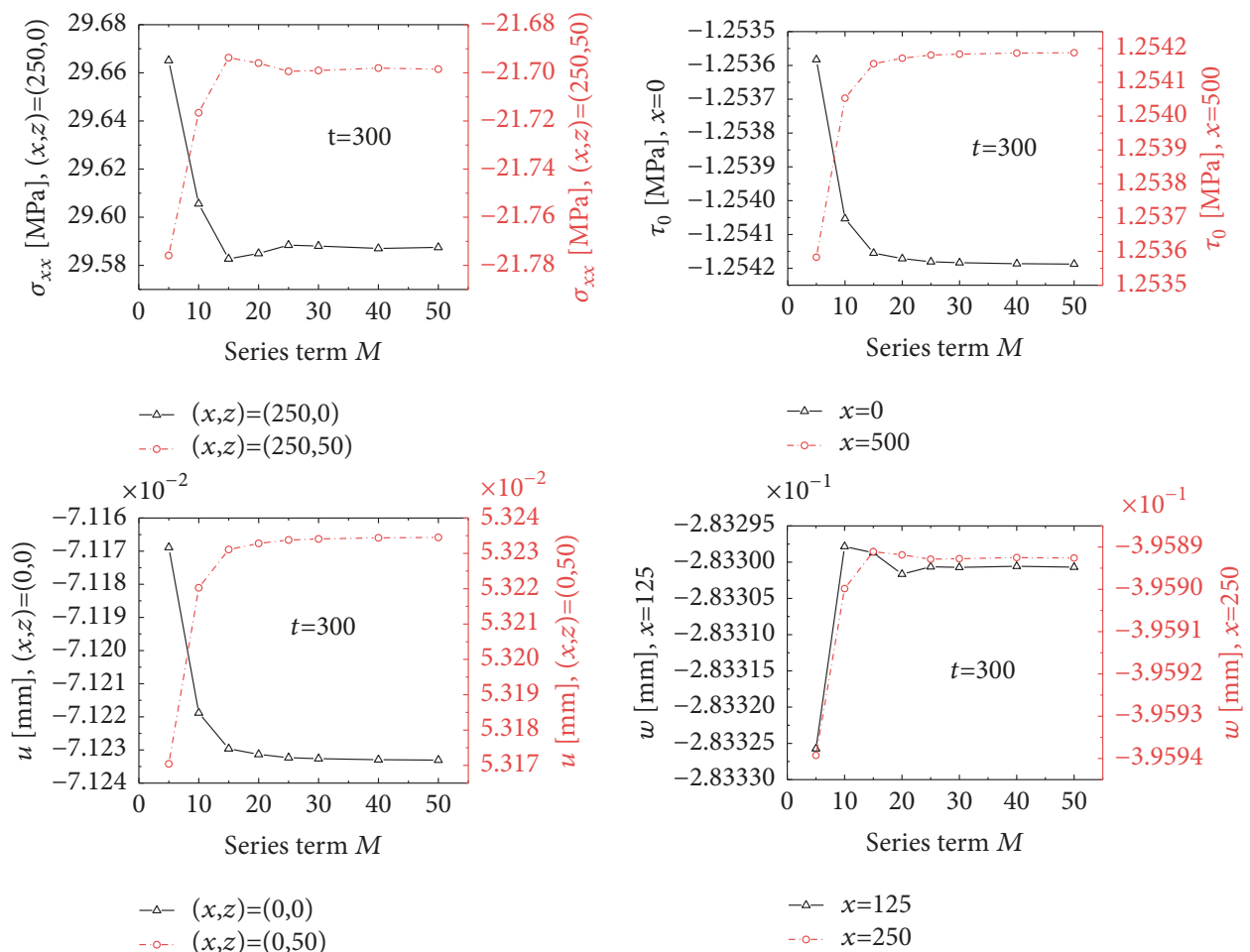

(a) $t=300 \mathrm{~s}$
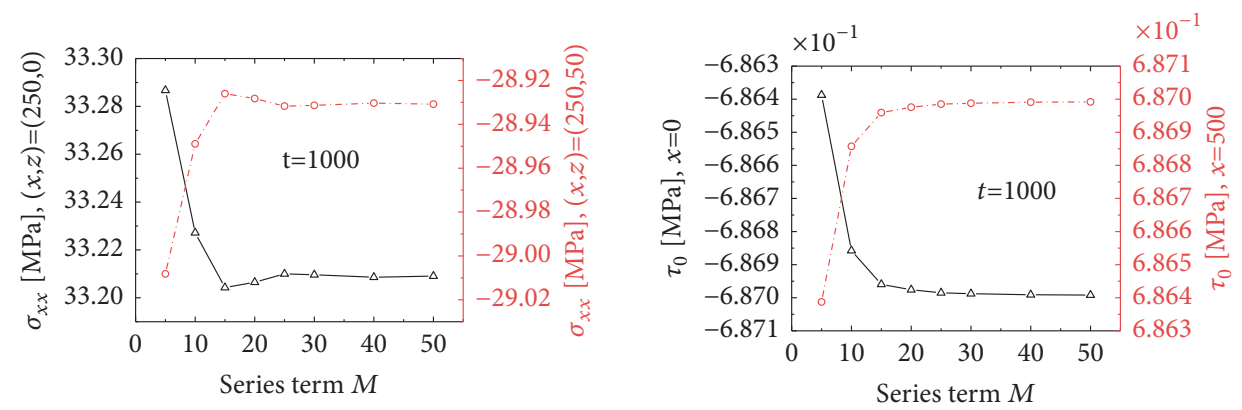

$-\Delta-(x, z)=(250,0)$

-.o. $\quad(x, z)=(250,50)$

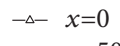

-... $x=500$
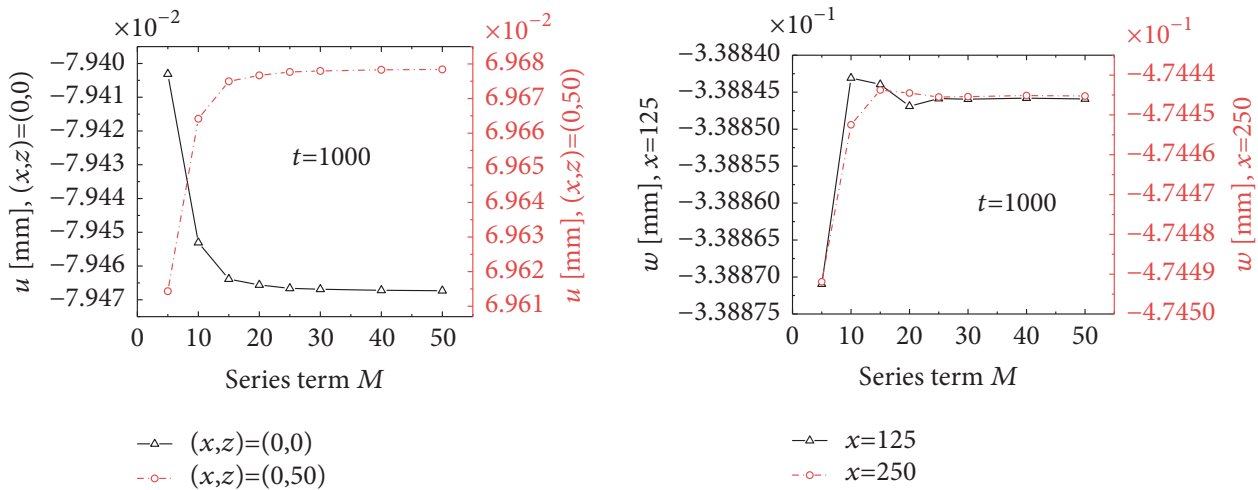

(b) $t=1000 \mathrm{~s}$

FIGURE 3: The convergences of $\sigma_{x x}, \tau_{0}, u, w$ with respect to the series term $M$ for $t=300 \mathrm{~s}$ and $t=1000 \mathrm{~s}$, respectively. 
TABLE 2: Comparisons of maximum longitudinal normal stress $\sigma_{x x}$ from the present results (TFV) with the EFV and FE ones for different length-to-thickness ratios $l / h_{0}$ and time values $t$.

\begin{tabular}{|c|c|c|c|c|c|c|}
\hline$l / h_{0}$ & $t$ & TFV & EFV & $\mathrm{FE}$ & Error to EFV (\%) & Error to FE (\%) \\
\hline \multirow[t]{3}{*}{20} & $10 \mathrm{~s}$ & 243.2934 & 243.2934 & 243.9783 & 0.000 & 0.2815 \\
\hline & $100 \mathrm{~s}$ & 247.9726 & 247.9726 & 248.6582 & 0.000 & 0.2765 \\
\hline & $1000 \mathrm{~s}$ & 274.7517 & 274.7517 & 275.4347 & 0.000 & 0.2486 \\
\hline \multirow[t]{3}{*}{10} & $10 \mathrm{~s}$ & 61.2769 & 61.2769 & 61.5935 & 0.000 & 0.5168 \\
\hline & $100 \mathrm{~s}$ & 65.7803 & 65.7803 & 66.0864 & 0.000 & 0.4653 \\
\hline & $1000 \mathrm{~s}$ & 85.4707 & 85.4707 & 85.7213 & 0.000 & 0.2932 \\
\hline \multirow[t]{3}{*}{5} & $10 \mathrm{~s}$ & 15.7629 & 15.7629 & 15.9729 & 0.000 & 1.3325 \\
\hline & $100 \mathrm{~s}$ & 19.6412 & 19.6412 & 19.8069 & 0.000 & 0.8435 \\
\hline & $1000 \mathrm{~s}$ & 27.0106 & 27.0106 & 27.1155 & 0.000 & 0.3883 \\
\hline \multirow[t]{3}{*}{2.5} & $10 \mathrm{~s}$ & 4.3476 & 4.3476 & 4.4776 & 0.000 & 2.9907 \\
\hline & $100 \mathrm{~s}$ & 6.6032 & 6.6032 & 6.651 & 0.000 & 0.7242 \\
\hline & $1000 \mathrm{~s}$ & 7.3554 & 7.3554 & 7.4064 & 0.000 & 0.6931 \\
\hline
\end{tabular}

Note: Error to EFV=(EFV-TFV)/TFV; Error to FE=(FE-TFV)/TFV.

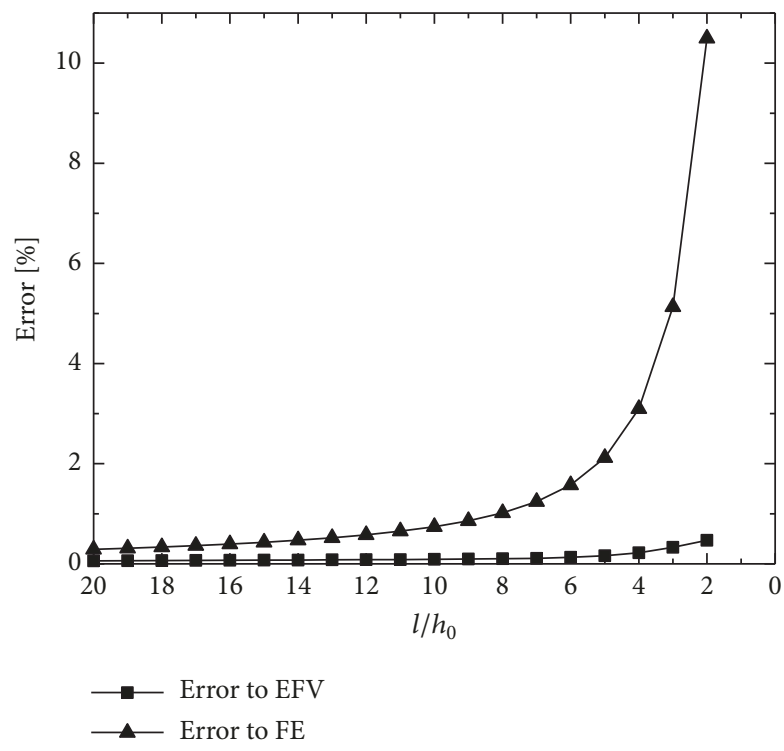

FIGURE 4: Comparisons of deflection $w_{m}$ of the present results (TFV) with the EFV and FE ones for different length-to-thickness ratios $l / h_{0}$ when $t=10000 s$. Error to $E F V=(E F V-T F V) / T F V$ and Error to $\mathrm{FE}=(\mathrm{FE}-\mathrm{TFV}) / \mathrm{TFV}$.

assumption. Therefore, the normal stress distributions on the cross-section for two different beam theories should be identical, if the moments on the cross-section are the same. Moreover, it can be easily deduced that the rotational angles and the longitudinal displacements of the simply supported layered beam are all independent of the shear coefficient, as seen in (31)-(33). Therefore, the shear stresses in the interlayer from the Timoshenko beam theory are also the same as those from the Euler-Bernoulli beam theory. Such a conclusion is valid only for statically determinate beams; however, it is invalid for statically indeterminate beams.

Furthermore, we compare the present results (TFV) with those (TFV (NME)) proposed by Wang et al. [28] and those obtained from the finite element (FE) solution by using the software ANSYS. The TFV (NME) solutions are also based on the FSDT; however, the memory effect of strains in the interlayer is neglected; i.e., the viscoelastic material is approximately modelled as an "aging" material. We consider a simply supported two-layer Timoshenko beam glued by a viscoelastic interlayer and subjected to the uniform load $q=1 \mathrm{~N} / \mathrm{mm}^{2}$. The parameters of the beam are $h_{1}=h_{2}=50 \mathrm{~mm}$, $b=30 \mathrm{~mm}, l=1000 \mathrm{~mm}, E_{1}=E_{2}=70 \mathrm{Gpa}, \mu_{1}=\mu_{2}=0.3, G_{\infty}=0.5$ Mpa, $G_{0}=500 \mathrm{Mpa}, h=0.5 \mathrm{~mm}, \theta=0.5 \mathrm{~s}$, respectively. Figure 5 shows the comparisons of $\sigma_{x x}, \tau_{0}, u$, and $w$ from three different solutions with respect to time $t$. It can be seen from Figure 5 that the present results (TFV) are in agreement with the FE ones. However, there are considerable differences between the present results (TFV) and those (TFV(NME)) without considering the memory effect of strains in the interlayer. Therefore, the results ignoring the memory effect of strains in the interlayer cannot accurately describe the varying of stresses and displacements of the beam with the time. The same responses have been obtained and recorded by Galuppi and Royer-Carfagni $[16,36]$ for beam with external plies modelled as EB beams.

4.3. Parametric Study. Consider a simply supported beam loaded by the uniform load $q=1 \mathrm{~N} / \mathrm{mm}^{2}$, which is composed of two outside elastic layers bonded by a viscoelastic interlayer. The parameters of the beam are $h_{1}=h_{2}=50 \mathrm{~mm}$, $b=30 \mathrm{~mm}, l=1000 \mathrm{~mm}, E_{1}=E_{2}=70 \mathrm{Gpa}, \mu_{1}=\mu_{2}=0.3$, respectively.

Figure 6 shows the distributions of stresses and displacements at the time $t=10,100$, and $1000 \mathrm{~s}$, respectively, for $h=0.5 \mathrm{~mm}, G_{0}=500 \mathrm{Mpa}, G_{\infty}=0.5 \mathrm{Mpa}$, and $\theta=0.5 \mathrm{~s}$. It can be seen from Figure 6 that (1) the absolute values of the longitudinal normal stress $\sigma_{x x}$ at the outside surfaces of the beam and the axial displacement $u$ at the ends of the beam increase with time; (2) the transverse shear stress $\tau_{x z}$ in the external elastic layers is almost no change with the time; (3) the mid-span deflection $w$ increases with time; (4) the maximum value of the shear stress $\tau_{0}$ in the interlayer appears at the ends of the beam and decreases with time. 


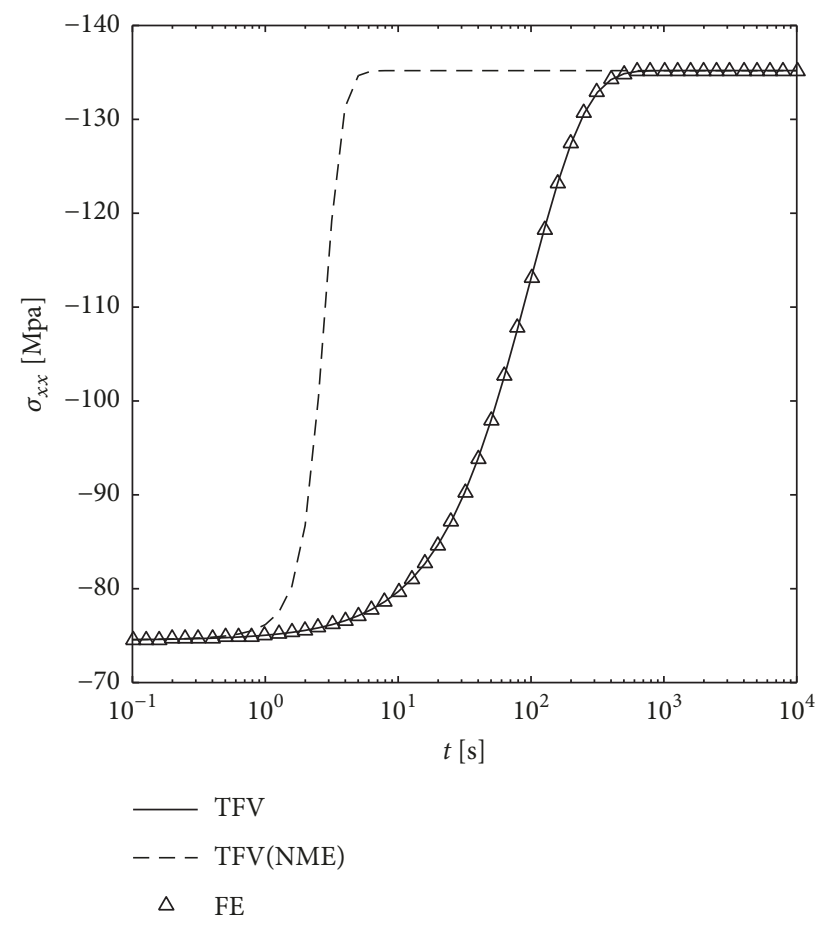

(a) $\sigma_{x x}$ at $x=500 \mathrm{~mm}, z=100.5 \mathrm{~mm}$

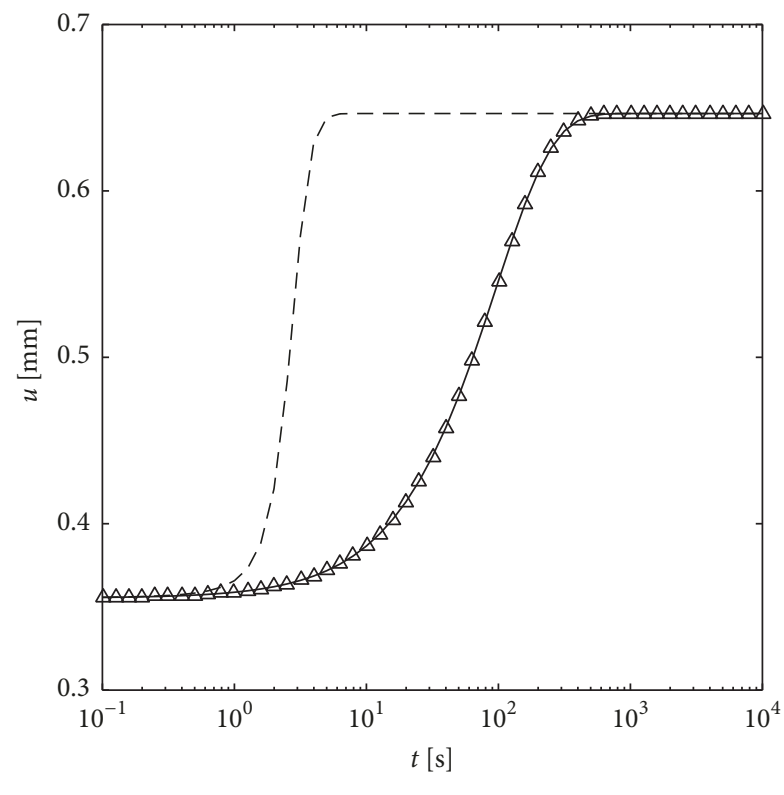

$-\mathrm{TFV}$
$--\mathrm{TFV}(\mathrm{NME})$

$\triangle \quad \mathrm{FE}$

(c) $u$ at $x=0, z=100.5 \mathrm{~mm}$

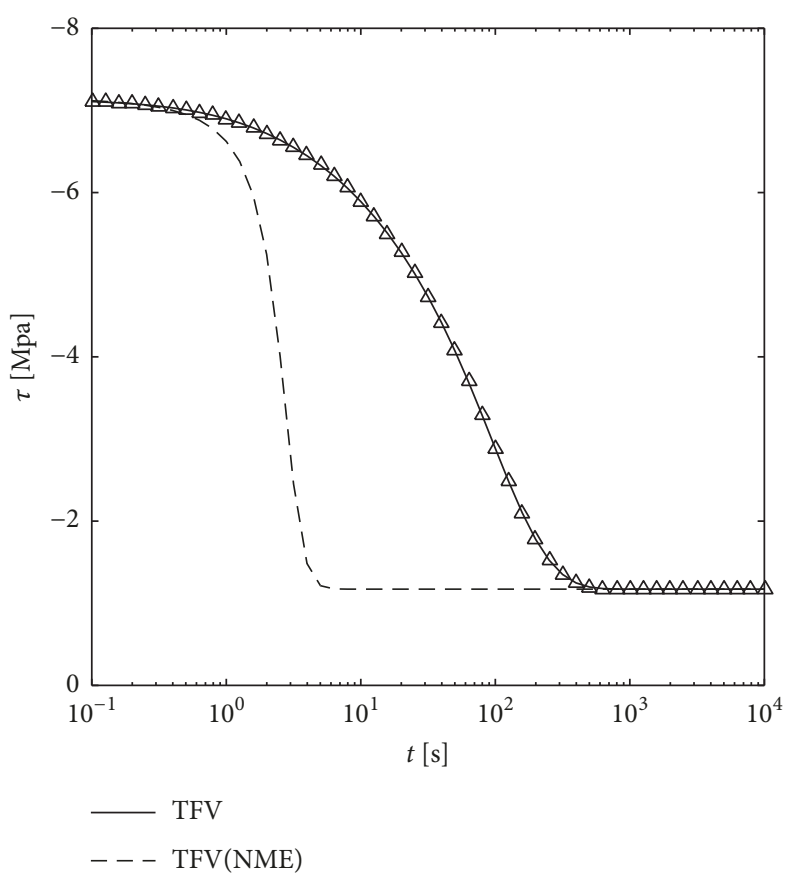

(b) $\tau_{0}$ at $x=0$

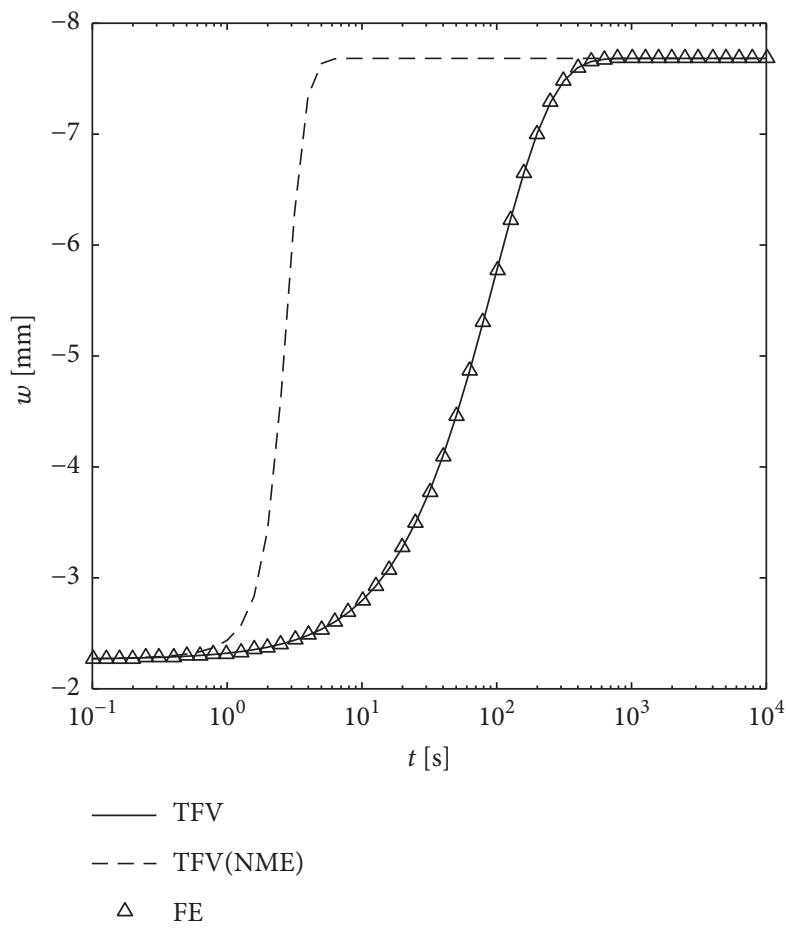

(d) $w$ at $x=500 \mathrm{~mm}$

Figure 5: Comparisons of $\sigma_{x x}, \tau_{0}, u$ and $w$ from three different solutions with respect to the time $t$.

Figure 7 shows the effects of parameters $h, G_{0}, G_{\infty}$, and $\theta$ on the mid-span deflection $w_{m}$ with respect to the time. It can be seen from Figure 7 that the mid-span deflection $w_{m}$ increases with time and tends to be constants for all cases. $w_{m}$ increases with the increase of glue thickness $h$; however, it decreases with the increase of long-term shear modulus $G_{\infty}$. The relaxation time $\theta$ has no effect on the values of $w_{m}$ at the limited times $t=0$ and $t=\infty$. 


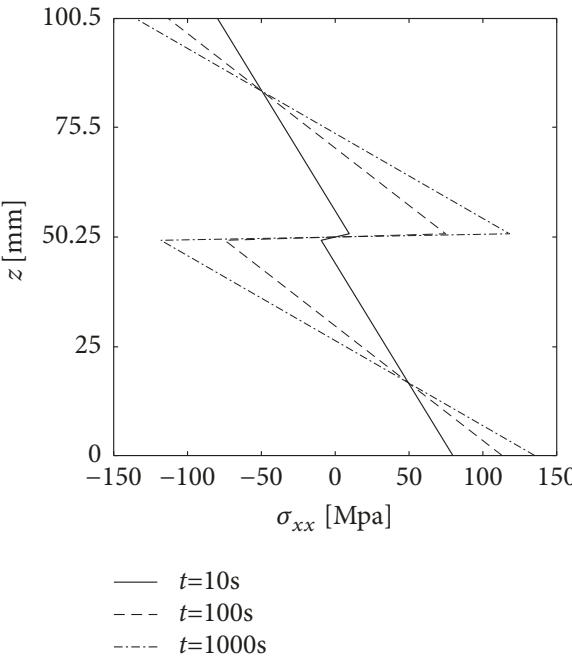

(a) $\sigma_{x x}$ at $x=500 \mathrm{~mm}$

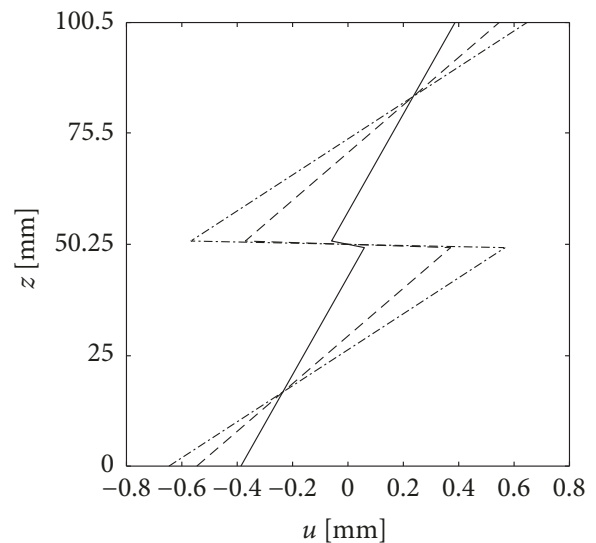

$\begin{array}{cc}- & t=10 \mathrm{~s} \\ --- & t=100 \mathrm{~s}\end{array}$

$-\cdot-t=1000$ s

(c) $u$ at $x=0$

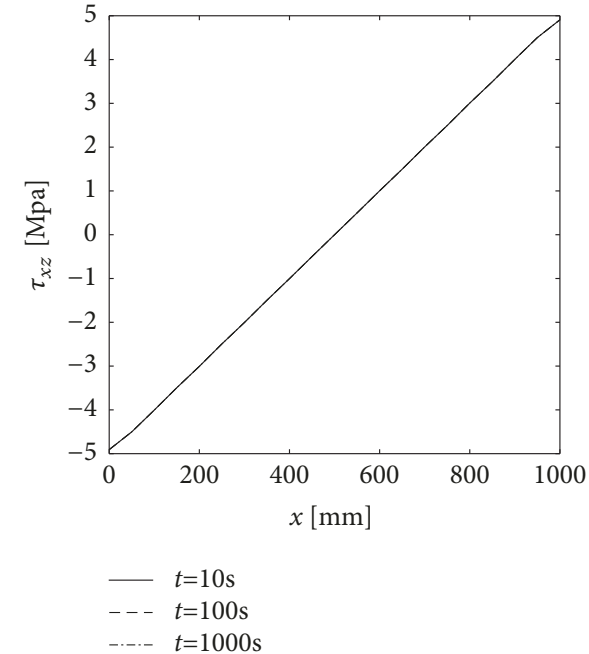

(b) $\tau_{x z}$

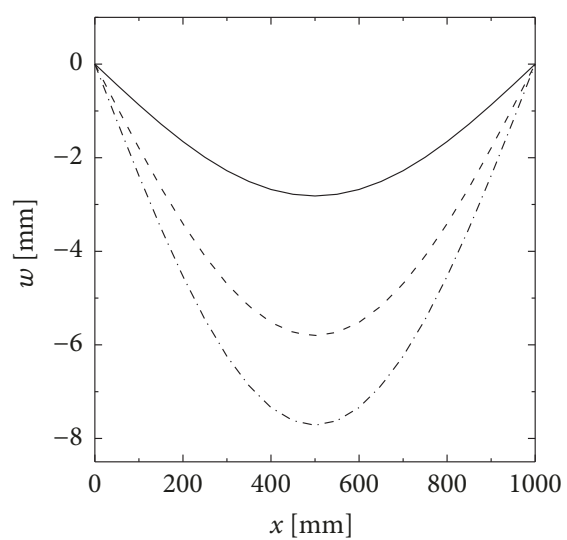

- $t=10 \mathrm{~s}$

- - $t=100 \mathrm{~s}$

-...- $t=1000 \mathrm{~s}$

(d) $w$

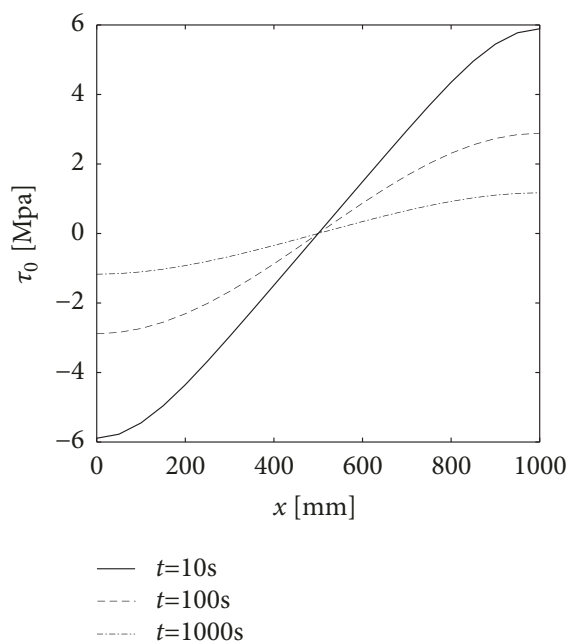

(e) $\tau_{0}$

FIGURE 6: Distributions of stresses and displacements of the laminated beam. 


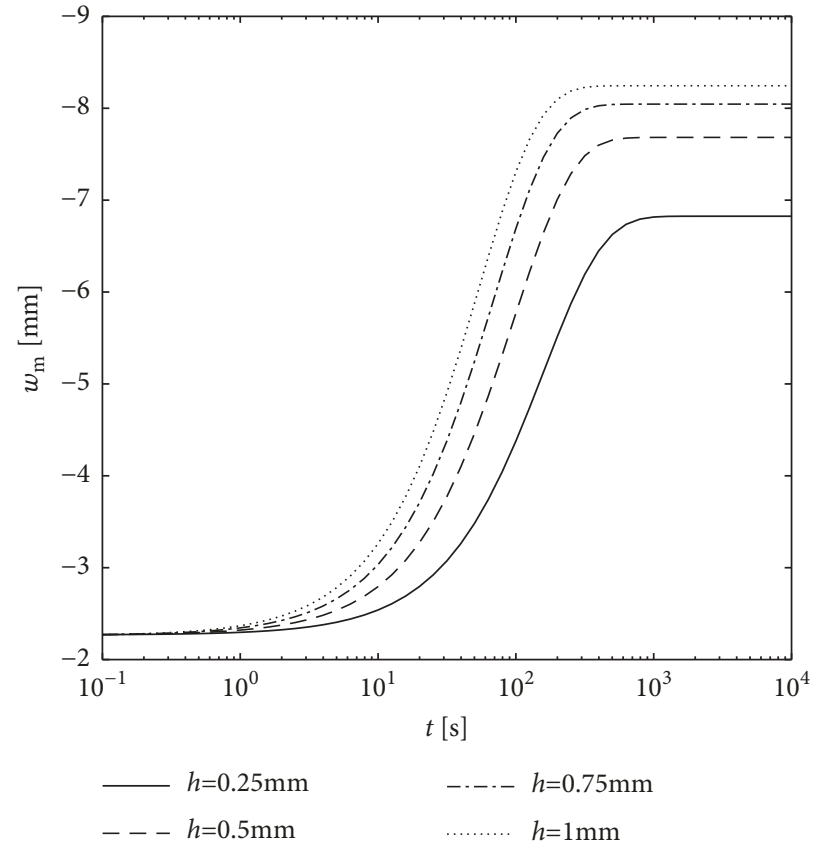

(a) $G_{0}=500 \mathrm{Mpa}, G_{\infty}=0.5 \mathrm{Mpa}, \theta=0.5 \mathrm{~s}$

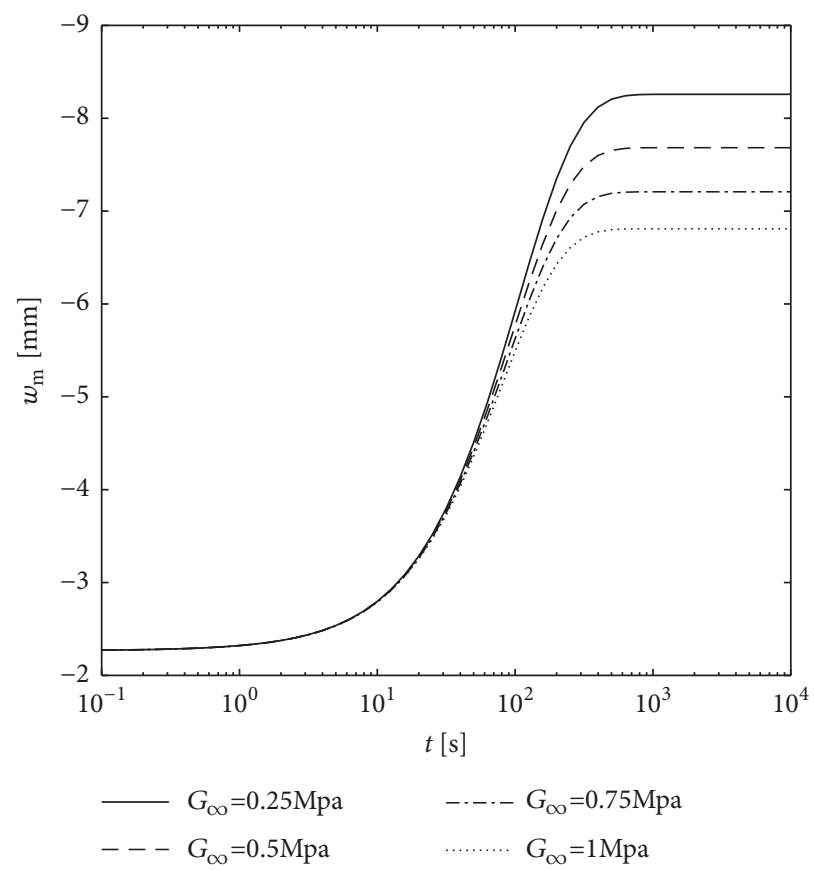

(c) $h=0.5 \mathrm{~mm}, G_{0}=500 \mathrm{Mpa}, \theta=0.5 \mathrm{~s}$

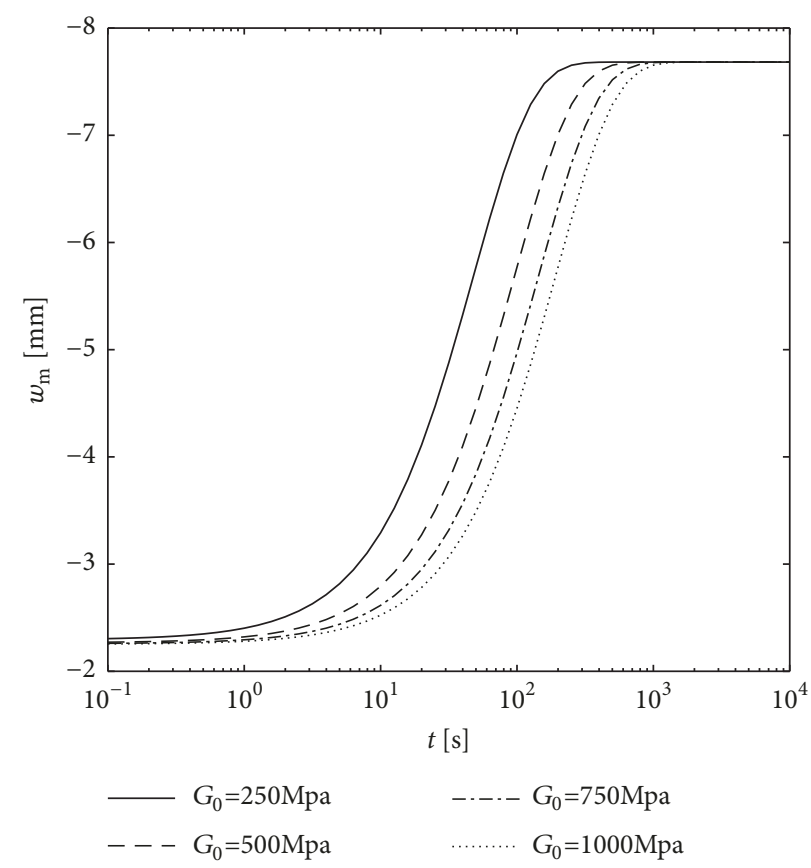

(b) $h=0.5 \mathrm{~mm}, G_{\infty}=0.5 \mathrm{Mpa}, \theta=0.5 \mathrm{~s}$

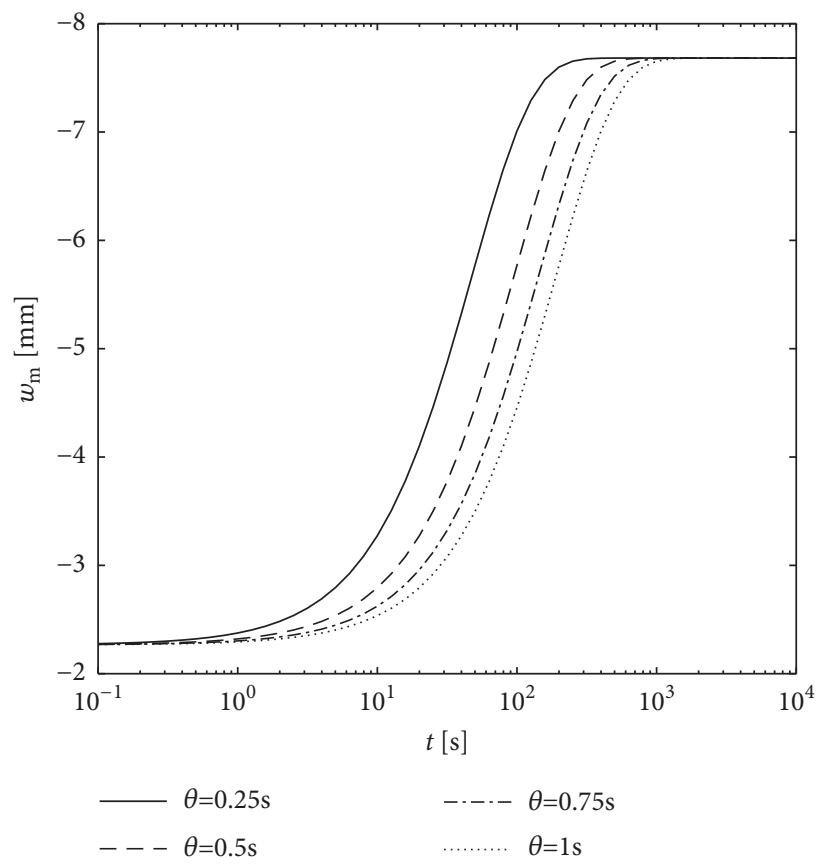

(d) $h=0.5 \mathrm{~mm}, G_{0}=500 \mathrm{Mpa}, G_{\infty}=0.5 \mathrm{Mpa}$

FIgURE 7: Effects of parameters $h, G_{0}, G_{\infty}$, and $\theta$ on the mid-span deflection $w_{m}$ with respect to the time $t$.

Further consider the layered beam with a viscoelastic interlayer as mentioned above. The thickness of the interlayer is $h=0.1 \mathrm{~mm}$. The mid-span deflection $w_{m}$ (at $x=500 \mathrm{~mm}$ ) with respect to the time for different viscoelasticity parameters $G_{0}$ and $G_{\infty}$ are shown in Figure 8. The monolithic limit, which corresponds to the static solution of $G \longrightarrow$ $\infty$, and the layered limit, which corresponds to the static solution of $G=0$, are also plotted for references. Physically, for the layered limit the beam is composed of free-sliding plies and for the monolithic limit the beam is composed of no relatively slipping plies $[16,36]$. It is seen from Figure 8 that the deflections of the beam for all cases are between the monolithic limit and the layered limit. Namely, the deflection of the beam with a viscoelastic interlayer is always larger 

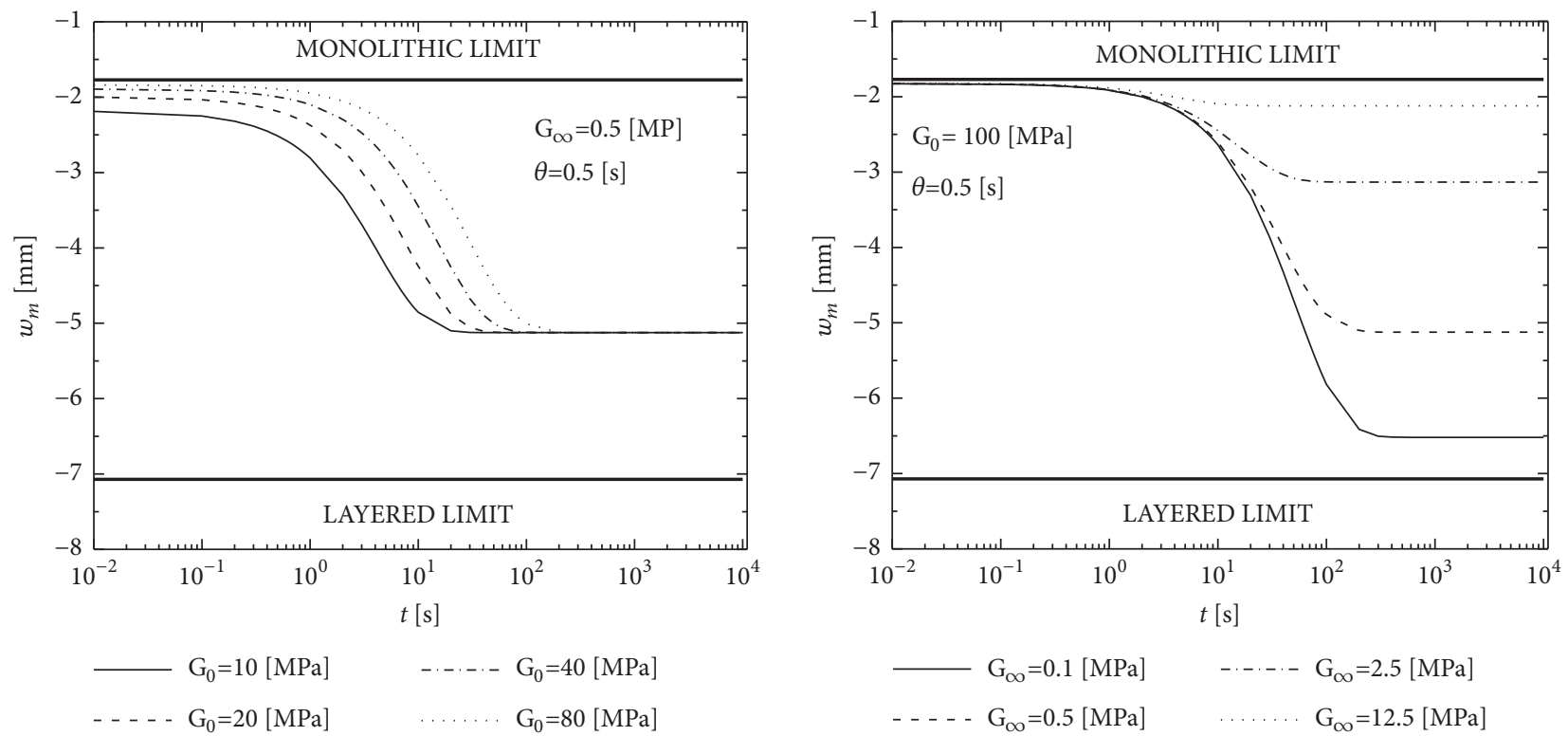

FIGURE 8: The effect of viscoelasticity parameters of interlayer on the mid-span deflection $w_{m}$ of the layered beam with a viscoelastic interlayer.

TABLE 3: Comparisons of maximum shear stress $\tau_{0}$ in interlayer from the present results (TFV) with the EFV and FE ones for different length-to-thickness ratios $l / h_{0}$ and time values $t$.

\begin{tabular}{|c|c|c|c|c|c|c|}
\hline$l / h_{0}$ & $t$ & TFV & EFV & $\mathrm{FE}$ & Error to EFV (\%) & Error to FE (\%) \\
\hline \multirow[t]{3}{*}{20} & $10 \mathrm{~s}$ & -9.5159 & -9.5159 & -9.5234 & 0.000 & 0.0785 \\
\hline & $100 \mathrm{~s}$ & -9.3327 & -9.3327 & -9.3396 & 0.000 & 0.0736 \\
\hline & $1000 \mathrm{~s}$ & -8.2843 & -8.2843 & -8.2879 & 0.000 & 0.0439 \\
\hline \multirow[t]{3}{*}{10} & $10 \mathrm{~s}$ & -4.7225 & -4.7225 & -4.7232 & 0.000 & 0.0157 \\
\hline & $100 \mathrm{~s}$ & -4.3698 & -4.3698 & -4.3701 & 0.000 & 0.0066 \\
\hline & $1000 \mathrm{~s}$ & -2.8280 & -2.8280 & -2.8267 & 0.000 & 0.0447 \\
\hline \multirow[t]{3}{*}{5} & $10 \mathrm{~s}$ & -2.2917 & -2.2917 & -2.2867 & 0.000 & 0.2204 \\
\hline & $100 \mathrm{~s}$ & -1.6844 & -1.6844 & -1.6825 & 0.000 & 0.1103 \\
\hline & $1000 \mathrm{~s}$ & -0.5302 & -0.5302 & -0.5307 & 0.000 & 0.0869 \\
\hline \multirow[t]{3}{*}{2.5} & $10 \mathrm{~s}$ & -1.0184 & -1.0184 & -1.009 & 0.000 & 0.9266 \\
\hline & $100 \mathrm{~s}$ & -0.3119 & -0.3119 & -0.317 & 0.000 & 1.6224 \\
\hline & $1000 \mathrm{~s}$ & -0.0763 & -0.0763 & -0.077 & 0.000 & 0.8887 \\
\hline
\end{tabular}

Note: Error to EFV=(EFV-TFV)/TFV; Error to FE $=(\mathrm{FE}-\mathrm{TFV}) / \mathrm{TFV}$.

than its monolithic limit, but smaller than its layered limit. Moreover, it can be seen from Figure 8 that $G_{0}$ has the significant influence on the short-term response of deflection of the layered beam and $G_{\infty}$ has significant influence on the long-term response of deflection of the layered beam.

\section{Conclusion Remarks}

According to the FSDT, this paper studies the stresses and deformations of simply supported two layers of Timoshenko beams glued with a viscoelastic interlayer and subjected to arbitrary loads. The viscoelasticity of the interlayer is described by the standard linear solid model and the memory effect of strains in the interlayer is considered. Taking the sinusoidal load and uniform load for example, the effects of external layer thickness and the interlayer material properties on deflection of the laminated beam are checked in detail. The results show that there are good agreements between the present results and those obtained with the Euler-Bernoulli beam theory when the length-to-thickness ratio is large; however, the errors between the two results increase in the decrease of length-to-thickness ratio. Moreover, the error of deflection from the Euler-Bernoulli beam theory at the initial time of applying load is significantly larger than that when the interlayer is fully relaxed. Therefore, the present results have a better accuracy than those in terms of the Euler-Bernoulli beam theory. The effect of interlayer material property on the deflection of the laminated beam is similar to those obtained from the Euler-Bernoulli beam theory $[16,36]$. 


\section{Appendix}

The coefficients in (36) are given as follows:

$$
\begin{aligned}
& C_{1 j}=\frac{C_{4} b p_{j} G_{\infty}}{\lambda_{j}^{3}\left(C_{1} G_{\infty}+C_{2} \lambda_{j}^{2}+C_{3} G_{\infty}\right)} \\
& C_{2 j}=\frac{C_{4} b p_{j} G_{0} C_{2}}{\lambda_{j}\left(C_{1} G_{\infty}+C_{1} G_{0}+C_{2} \lambda_{j}^{2}+C_{3} G_{\infty}+C_{3} G_{0}\right)\left(C_{1} G_{\infty}+C_{2} \lambda_{j}^{2}+C_{3} G_{\infty}\right)}, \\
& C_{3 j}=\frac{C_{1} G_{\infty}+C_{2} \lambda_{j}^{2}+C_{3} G_{\infty}}{\left(C_{1} G_{\infty}+C_{1} G_{0}+C_{2} \lambda_{j}^{2}+C_{3} G_{\infty}+C_{3} G_{0}\right) \theta} \\
& C_{4 j}=\frac{C_{5} b p_{j} G_{\infty}}{\lambda_{j}^{3}\left(C_{1} G_{\infty}+C_{2} \lambda_{j}^{2}+C_{3} G_{\infty}\right)} \\
& C_{5 j}=\frac{C_{5} b p_{j} G_{0} C_{2}}{\lambda_{j}\left(C_{1} G_{\infty}+C_{1} G_{0}+C_{2} \lambda_{j}^{2}+C_{3} G_{\infty}+C_{3} G_{0}\right)\left(C_{1} G_{\infty}+C_{2} \lambda_{j}^{2}+C_{3} G_{\infty}\right)}, \\
& C_{6 j}=\frac{b p_{j}\left(C_{6} \lambda_{j}^{2}+C_{7} G_{\infty}\right)}{\lambda_{j}^{3}\left(C_{1} G_{\infty}+C_{2} \lambda_{j}^{2}+C_{3} G_{\infty}\right)}, \\
& C_{7 j}=\frac{b p_{j} G_{0}\left(C_{7} C_{2}-C_{6} C_{1}-C_{6} C_{3}\right)}{\lambda_{j}\left(C_{1} G_{\infty}+C_{1} G_{0}+C_{2} \lambda_{j}^{2}+C_{3} G_{\infty}+C_{3} G_{0}\right)\left(C_{1} G_{\infty}+C_{2} \lambda_{j}^{2}+C_{3} G_{\infty}\right)}, \\
& C_{8 j}=\frac{b p_{j}}{B_{1} \lambda_{j}^{2}} \\
& C_{9 j}=\frac{b p_{j}\left(C_{6} \lambda_{j}^{2}+C_{7} G_{\infty}\right)}{\lambda_{j}^{4}\left(C_{1} G_{\infty}+C_{2} \lambda_{j}^{2}+C_{3} G_{\infty}\right)}, \\
& C_{10 j}=\frac{b p_{j} G_{0}\left(C_{7} C_{2}-C_{6} C_{1}-C_{6} C_{3}\right)}{\lambda_{j}^{2}\left(C_{1} G_{\infty}+C_{1} G_{0}+C_{2} \lambda_{j}^{2}+C_{3} G_{\infty}+C_{3} G_{0}\right)\left(C_{1} G_{\infty}+C_{2} \lambda_{j}^{2}+C_{3} G_{\infty}\right)}
\end{aligned}
$$

\section{Data Availability}

The data used to support the findings of the study are available from the corresponding author upon request.

\section{Conflicts of Interest}

The authors declared no potential conflicts of interest with respect to the research, authorship, and/or publication of this article.

\section{Authors' Contributions}

All authors carried out the proofreading of the paper. All authors conceived the study and participated in its design and coordination. All authors read and approved the final paper.

\section{Acknowledgments}

This research work is financially supported by the National Key Basic Research Program of China (2012CB026205), the National Natural Science Foundation of China (51778288), and the Transportation Science and Technology Project of Jiangsu Province (2014Y01). The authors are grateful for these supports.

\section{References}

[1] B. Uy and S. Craine, "Static flexural behaviour of externally post-tensioned steel-concrete composite beams," Advances in Structural Engineering, vol. 7, no. 1, pp. 1-20, 2004.

[2] G. Bertagnoli, D. Gino, and E. Martinelli, "A simplified method for predicting early-age stresses in slabs of steel-concrete composite beams in partial interaction," Engineering Structures, vol. 140, pp. 286-297, 2017. 
[3] W. M. Sebastian, J. Mudie, G. Cox, M. Piazza, R. Tomasi, and I. Giongo, "Insight into mechanics of externally indeterminate hardwood-concrete composite beams," Construction and Building Materials, vol. 102, pp. 1029-1048, 2016.

[4] N. Khorsandnia, H. Valipour, J. Schänzlin, and K. Crews, "Experimental investigations of deconstructable timberconcrete composite beams," Journal of Structural Engineering (United States), vol. 142, no. 12, 2016.

[5] Q. Hussain and A. Pimanmas, "Shear strengthening of RC deep beams with openings using sprayed glass fiber reinforced polymer composites (SGFRP): part 1. experimental study," KSCE Journal of Civil Engineering, vol. 19, no. 7, pp. 2121-2133, 2015.

[6] M. A. Alam, A. Hassan, and Z. C. Muda, "Development of kenaf fibre reinforced polymer laminate for shear strengthening of reinforced concrete beam," Materials and Structures/Materiaux et Constructions, vol. 49, no. 3, pp. 795-811, 2016.

[7] S. Chen, M. Zang, D. Wang, Z. Zheng, and C. Zhao, "Finite element modelling of impact damage in polyvinyl butyral laminated glass," Composite Structures, vol. 138, pp. 1-11, 2016.

[8] C. Bedon and C. Louter, "Finite Element analysis of posttensioned SG-laminated glass beams with adhesively bonded steel tendons," Composite Structures, vol. 167, pp. 238-250, 2017.

[9] I. Ecsedi and A. Baksa, "Static analysis of composite beams with weak shear connection," Applied Mathematical Modelling, vol. 35, no. 4, pp. 1739-1750, 2011.

[10] P. Wu, D. Zhou, and W. Liu, "2-D elasticity solution of layered composite beams with viscoelastic interlayers," Mechanics of Time-Dependent Materials, vol. 20, no. 1, pp. 1-20, 2016.

[11] R. A. Behr, J. E. Minor, and H. S. Norville, "Structural behavior of architectural laminated glass," ASCE Journal of Structural Engineering, vol. 119, no. 1, pp. 202-222, 1993.

[12] L. Galuppi and G. Royer-Carfagni, "Effective width of the slab in composite beams with nonlinear shear connection," ASCE Journal of Engineering Mechanics, vol. 142, no. 4, 2016.

[13] C. Zhang and J. Wang, "Viscoelastic analysis of FRP strengthened reinforced concrete beams," Composite Structures, vol. 93, no. 12, pp. 3200-3208, 2011.

[14] Y. Lei, T. Murmu, S. Adhikari, and M. I. Friswell, "Dynamic characteristics of damped viscoelastic nonlocal Euler-Bernoulli beams," European Journal of Mechanics - A/Solids, vol. 42, no. 6, pp. 125-136, 2013.

[15] C. M. Wang, T. Q. Yang, and K. Y. Lam, "Viscoelastic Timoshenko beam solutions from Euler-Bernoulli solutions," Journal of Engineering Mechanics, vol. 123, no. 7, pp. 746-748, 1997.

[16] L. Galuppi and G. Royer-Carfagni, "Laminated beams with viscoelastic interlayer," International Journal of Solids and Structures, vol. 49, no. 18, pp. 2637-2645, 2012.

[17] L. Galuppi and G. Royer-Carfagni, "Buckling of three-layered composite beams with viscoelastic interaction," Composite Structures, vol. 107, no. 1, pp. 512-521, 2013.

[18] J. Li, B. Zheng, Q. Yang, and X. Hu, "Analysis on timedependent behavior of laminated functionally graded beams with viscoelastic interlayer," Composite Structures, vol. 107, no. 1, pp. 30-35, 2014.

[19] S. Lenci and F. Clementi, "Effects of shear stiffness, rotatory and axial inertia, and interface stiffness on free vibrations of a twolayer beam," Journal of Sound and Vibration, vol. 331, no. 24, pp. 5247-5267, 2012.

[20] H. Murakami, "A laminated beam theory with interlayer slip," Journal of Applied Mechanics, vol. 51, no. 3, pp. 551-559, 1984.
[21] H. Wang and L. Chen, "Vibration and damping analysis of a three-layered composite annular plate with a viscoelastic midlayer," Composite Structures, vol. 58, no. 4, pp. 563-570, 2002.

[22] L. Bardella, "Reliability of first-order shear deformation models for sandwich beams," Journal of Mechanics of Materials and Structures, vol. 3, no. 7, pp. 1187-1206, 2008.

[23] O. Mattei and L. Bardella, "A structural model for plane sandwich beams including transverse core deformability and arbitrary boundary conditions," European Journal of Mechanics - A/Solids, vol. 58, pp. 172-186, 2016.

[24] A. Tessler, M. D. Suivua, and M. Gherlone, "Refinement of Timoshenko beam theory for composite and sandwich beams using zigzag kinematics," Tech. Rep. NASA/TP-2007-215086, 2007.

[25] Y. Frostig, M. Baruch, O. Vilnay, and I. Sheinman, "High-order theory for sandwich-beam behavior with transversely flexible core," Journal of Engineering Mechanics, vol. 118, no. 5, pp. 10261043, 1992.

[26] A. M. Zenkour, M. N. M. Allam, and M. Sobhy, "Bending analysis of FG viscoelastic sandwich beams with elastic cores resting on Pasternak's elastic foundations," Acta Mechanica, vol. 212, no. 3-4, pp. 233-252, 2010.

[27] A. Arikoglu and I. Ozkol, "Vibration analysis of composite sandwich beams with viscoelastic core by using differential transform method," Composite Structures, vol. 92, no. 12, pp. 3031-3039, 2010.

[28] L. Wang, P. Wu, and D. Zhou, "Analysis of mechanical properties of glued Timoshenko beams with a viscoelastic interlayer," Journal of Nanjing Tech University (Natural Science Edition), vol. 39, no. 05, pp. 85-91, 2017.

[29] M. L. Aenlle and F. Pelayo, "Frequency response of laminated glass elements: analytical modeling and effective thickness," Applied Mechanics Reviews, vol. 65, no. 2, 2013.

[30] M. López-Aenlle and F. Pelayo, "Dynamic effective thickness in laminated-glass beams and plates," Composites Part B: Engineering, vol. 67, pp. 332-347, 2014.

[31] M. Serpilli and S. Lenci, "Asymptotic modelling of the linear dynamics of laminated beams," International Journal of Solids and Structures, vol. 49, no. 9, pp. 1147-1157, 2012.

[32] M. Serpilli and S. Lenci, "An overview of different asymptotic models for anisotropic three-layer plates with soft adhesive," International Journal of Solids and Structures, vol. 81, pp. 130140, 2016.

[33] M. Serpilli, "Asymptotic interface models in magneto-electrothermo-elastic composites," Meccanica, vol. 52, no. 6, pp. 14071424, 2017.

[34] P. Meshgin, K.-K. Choi, and M. M. Reda Taha, "Experimental and analytical investigations of creep of epoxy adhesive at the concrete-FRP interfaces," International Journal of Adhesion and Adhesives, vol. 29, no. 1, pp. 56-66, 2009.

[35] G. R. Cowper, "The shear coefficients in Timoshenkos beam theory," ASME Journal of Applied Mechanics, vol. 33, no. 2, pp. 335-340, 1966.

[36] L. Galuppi and G. F. Royer-Carfagni, "Effective thickness of laminated glass beams: new expression via a variational approach," Engineering Structures, vol. 38, pp. 53-67, 2012.

[37] J. W. Gooch, Boltzmann Superposition Principle, Springer, New York, NY, USA, 2011.

[38] J. Souchek and L. H. Li, "Structure of rings of functions with Riemann Stieltjes convolution products," Journal of Mathematical Analysis and Applications, vol. 41, no. 2, pp. 468-477, 1973. 
[39] M. E. Gurtin and E. Sternberg, "On the linear theory of viscoelasticity," Archive for Rational Mechanics and Analysis, vol. 11, pp. 291-356, 1962.

[40] L. Andreozzi, S. Briccoli Bati, M. Fagone, G. Ranocchiai, and F. Zulli, "Dynamic torsion tests to characterize the thermoviscoelastic properties of polymeric interlayers for laminated glass," Construction and Building Materials, vol. 65, pp. 1-13, 2014. 


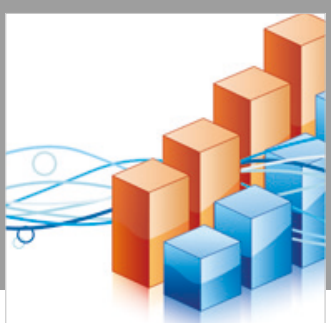

Advances in

Operations Research

\section{-n-m}
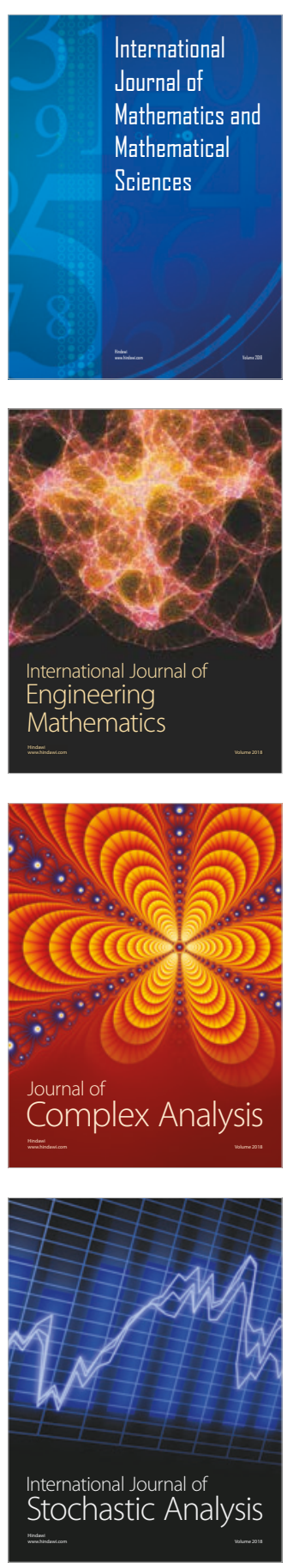
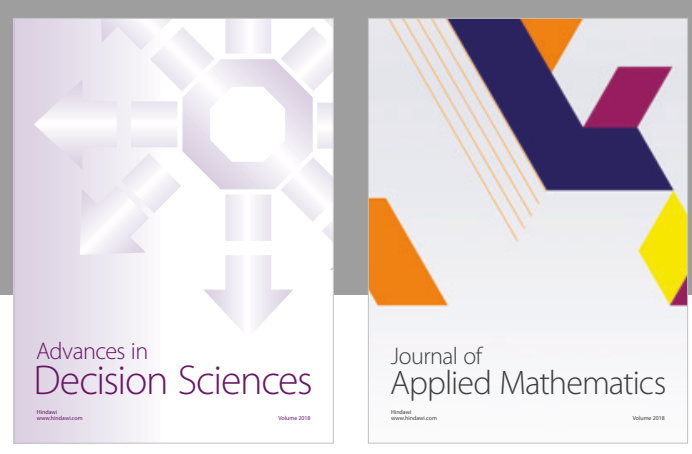

Journal of

Applied Mathematics
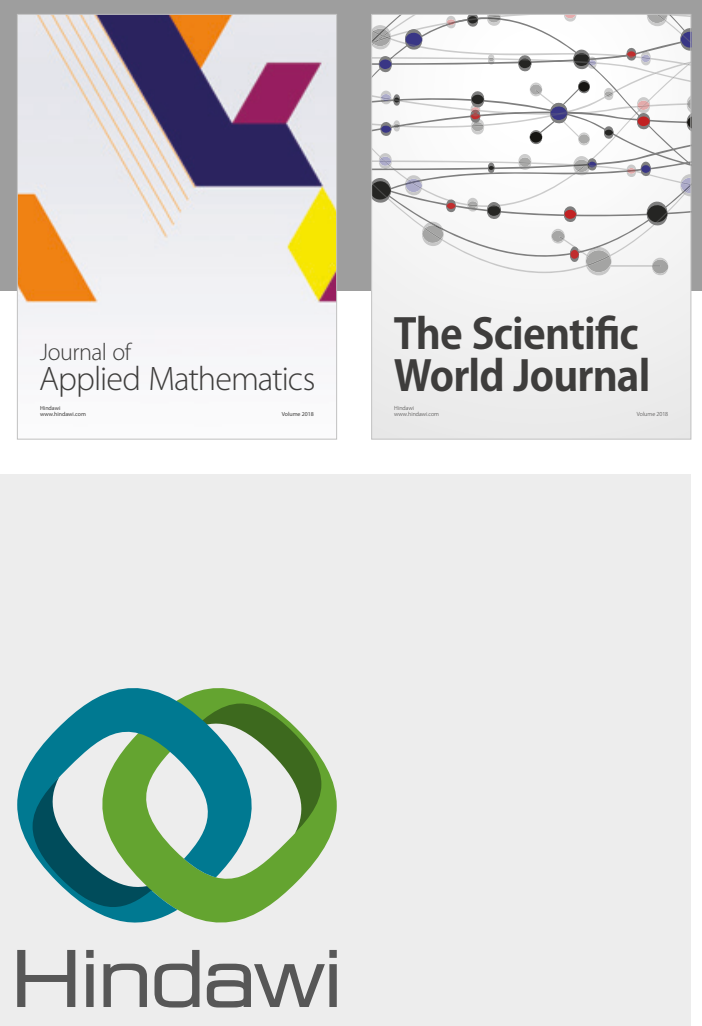

Submit your manuscripts at

www.hindawi.com

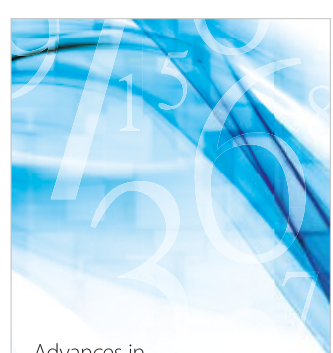

Advances in
Numerical Analysis
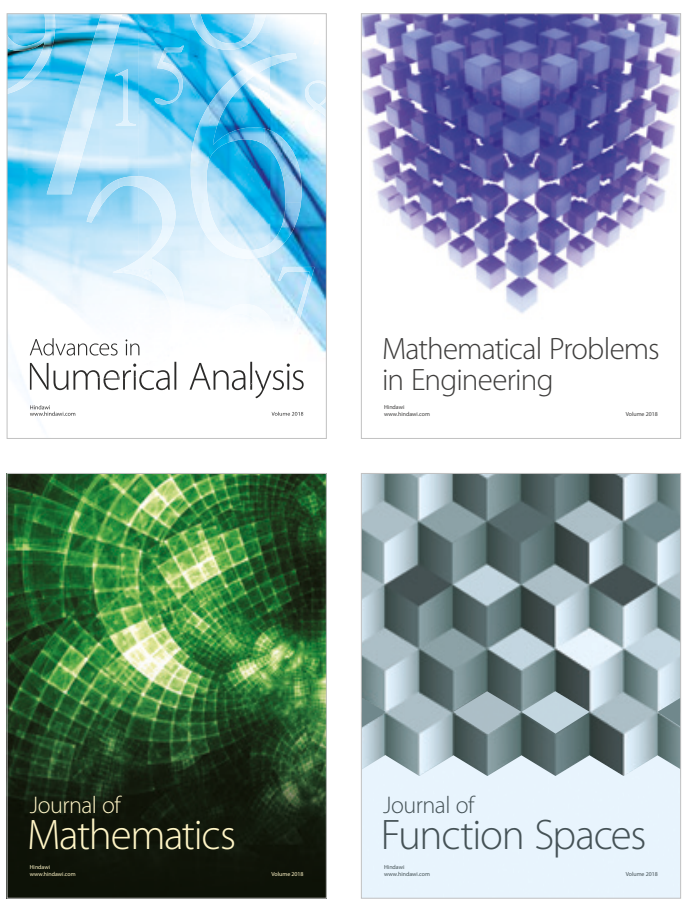

Mathematical Problems in Engineering

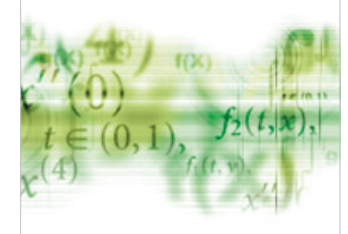

International Journal of

Differential Equations

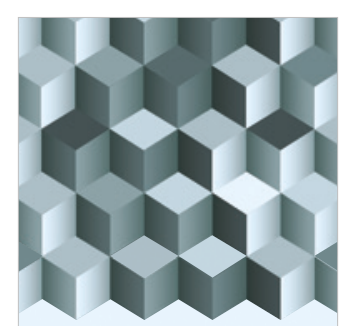

Journal of

Function Spaces

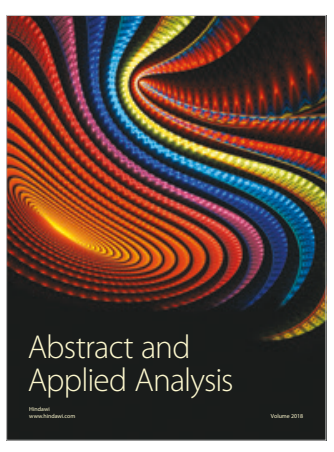

The Scientific

World Journal

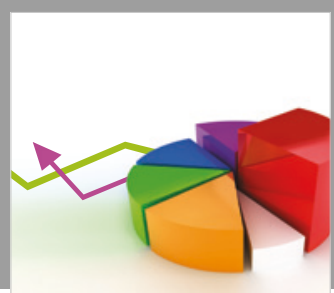

Journal of

Probability and Statistics
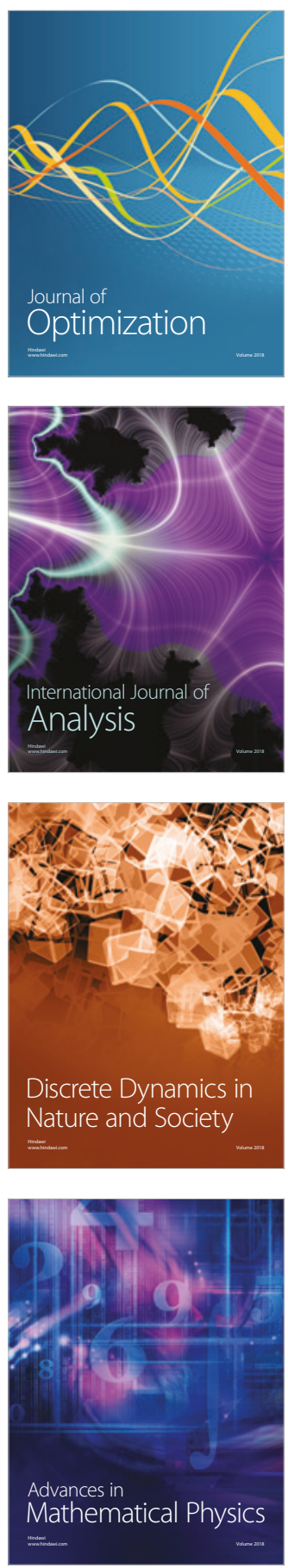